\title{
An investigation into the effect of alcohol consumption on health status and health care utilization in Ireland
}

\author{
Dr. Gillian Ormond ${ }^{a} \&$ Dr. Rosemary Murphy ${ }^{\text {b }}$ \\ ${ }^{a}$ Department of Accounting and Economics, Waterford Institute of Technology, Cork Road, \\ Waterford, Ireland \\ ${ }^{\mathrm{b}}$ Department of Economics, University College Cork, Western Road, Cork, Ireland
}

Address correspondence to:

Dr. Gillian Ormond

Waterford Institute of Technology

Cork Road

Waterford, Ireland

Telephone: +35351845603

E-mail: gormond@wit.ie 


\begin{abstract}
This paper presents a study of the effect of alcohol consumption on individual health status and health care utilization in Ireland using the 2007 Slán National Health and Lifestyle Survey, while accounting for the endogenous relationship between alcohol and health. Drinkers are categorized as those who never drank, non-drinkers, moderate drinkers, or heavy drinkers, based on national recommended weekly drinking levels in Ireland. The drinking-status equation is estimated using an ordered probit model. Predicted values for the inverse mills ratio are generated, which are then included in the health and health-care utilization equations.

Differences in health status for each category of drinker are examined, and the relationship between both alcohol consumption and health with a host of other personal and socio-economic variables is also identified. Given that the measure of health status available is self-assessed, the effect of alcohol consumption on health-care utilization is also analyzed as an alternative measure of health. Findings show that in Ireland, moderate drinkers enjoy the best health status. More moderate drinkers report having very good or excellent health compared with heavy drinkers, non-drinkers, or those who never drank. While heavy drinkers do not report having as good a health status as moderate drinkers, they are better off in terms of health when compared with non-drinkers and those who are lifetime abstainers.
\end{abstract}

\title{
Highlights
}

- The effects of alcohol consumption on health status in Ireland are examined.

- Individuals are categorized as those who never drank, non-drinkers, moderate drinkers, or heavy drinkers.

- Endogeneity and selection bias of alcohol consumption are accounted for.

- The findings are that a higher number of non-drinkers and those who never drank report poorer health compared with moderate or heavy drinkers.

- The findings highlight concerns with the implementation of population-based policies as recently proposed in Ireland. 
Keywords: Economics; Economic Methodology; Health-Care System; Social Policy; SocioEconomics; Statistics

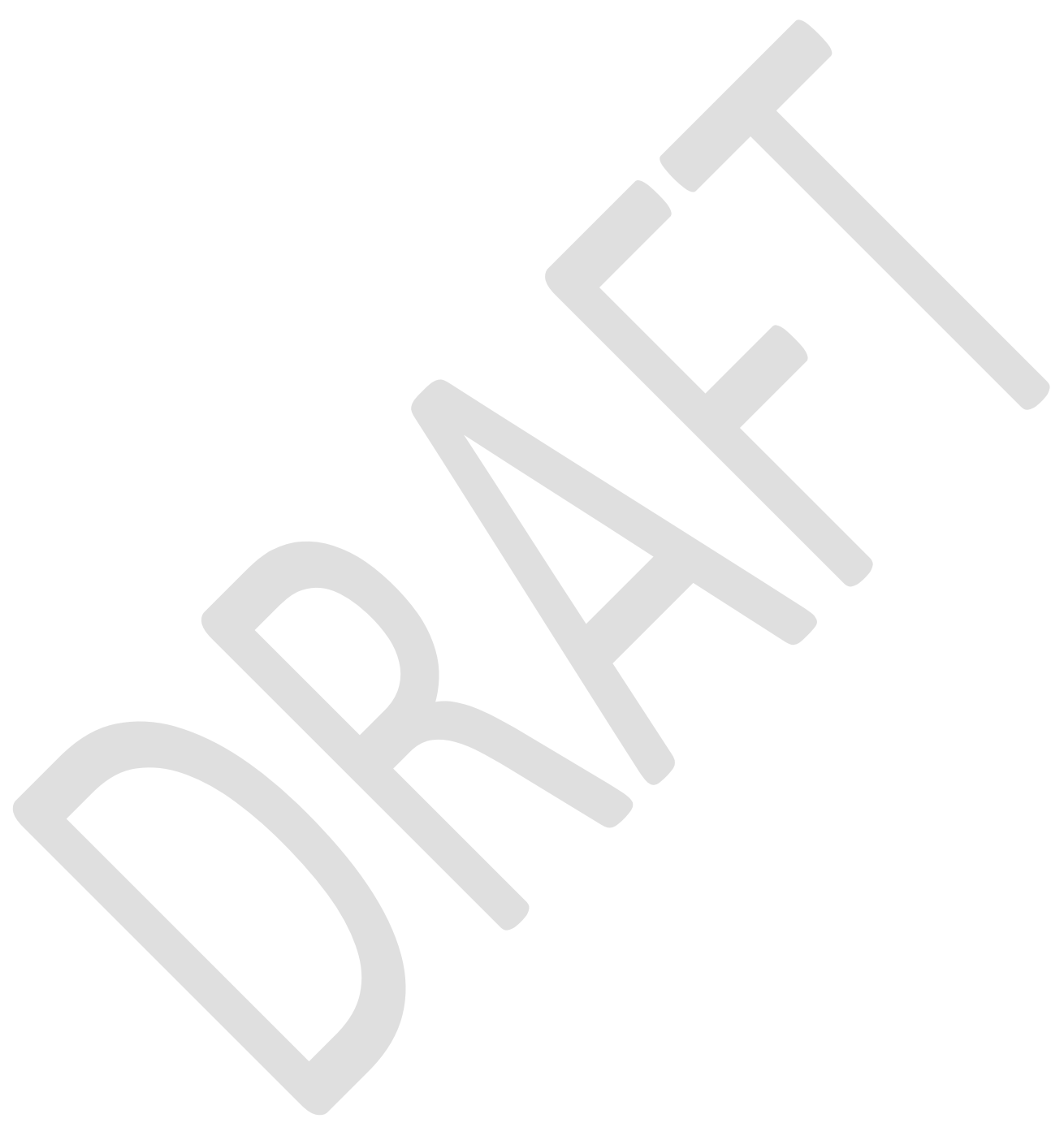




\section{Introduction}

The World Health Organization (2014) states that the harmful use of alcohol causes a large disease, social, and economic burden in societies. They state that in 2012, about 3.3 million deaths, or $5.9 \%$ of all global deaths, were attributable to alcohol consumption, and $5.1 \%$ of the global burden of disease and injury were attributable to alcohol consumption. The WHO (2014) also reports that there is a wide geographical variation in the proportion of alcohol-attributable deaths and Disability Adjusted Life Years (DALYs), with the highest alcohol-attributable fractions reported in the WHO European Region. A report commissioned by the Department of Health in Ireland (2014) states that a total of $€ 793$ million was spent on health and social care expenditure related to alcohol misuse in Ireland in 2013.

This paper investigates the effect of alcohol consumption on health status in Ireland while accounting for the potential endogenous relationship between alcohol and health. Drinkers are categorized into four categories based on the recommended weekly drinking levels of the Irish Health Promotion Unit (Health Service Executive [(2008]) in Ireland at the time of the survey: those who never drank, current non-drinkers, moderate drinkers, and heavy drinkers. Differences in health status for each of the categories are examined, and the relationship between both alcohol status and health with a host of other personal and socio-economic variables such as age, gender, marital status, employment status, and level of education, among others, is also identified. The burden of alcohol consumption on medical care is also assessed.

Sample selection bias arises when a sector selection is non-random due to individuals choosing a particular sector because of their personal characteristics (Heckman, 1979; Zhang, 2004). In relation to categorizing individuals based on their levels of alcohol consumption, selection bias may arise as people may select into a particular drinker group because they know 
that by doing so it will not have a negative effect on them (Barrett, 2002; Di Pietro \& Pedace, 2008; Hamilton \& Hamilton, 1997).

Endogeneity is the situation in which an independent variable included in the model is potentially a choice variable and is determined within the context of the model (Chenhall \& Moers, 2007). In relation to the study of a lifestyle variable such as alcohol on health, alcohol consumption is governed in part by unobserved factors, which may also be important determinants of the dependent variable 'health', implying the possibility that alcohol consumption may be correlated with the error term of the conditional-demand equation (Kenkel, 1995). If endogeneity occurs and is not accounted for, it would mean that alcohol is determined within the model used to estimate health status, resulting in the estimates received being inaccurate.

The remainder of this paper is presented as follows. Section 2 presents the theory in relation to the issue of the factors affecting health status and health-care utilization and the impact alcohol has on both. Section 3 outlines the empirical model used to analyze the effect of drinking status on health while controlling for selection bias and endogeneity. Section 4 identifies and describes the data and empirical results. Section 5 concludes the paper.

\section{Health Production Framework}

\subsection{Grossman's Human Capital Model}

Michael Grossman's human capital model of the demand for health states that individuals derive utility from the services that health capital yields and from the consumption of other commodities (Gerdtham, Johannesson, Lundberg, \& Isacson, 1999; Wagstaff, 1986). The determinants of health constitute an issue of vital importance to health policy. The stock of health capital depreciates over time, and the consumer can produce gross investments in it 
according to a household production function using medical care and their own time as inputs. Grossman (1972) argues that if one can improve one's health status, they are then in a position to work more, are absent from work less, and are more productive, which results in higher income. Grossman adds to this theory by saying that an increased wage rate results in one's returns from healthy days increasing, and hence workers will therefore tend to increase their optimal capital stock of health. Consumers are viewed as producing gross investments in health using inputs of medical care and their own time.

\subsection{Self-rated health}

The World Health Organization defines health as a state of complete physical, mental, and social well-being and not merely the absence of disease or infirmity. Health is a resource for everyday life, not the objective of living.

Self-Assessed Health is probably the most common measure of health in general-purpose surveys and is often the only available indicator of the respondent's health (Jürges, 2008). The Self-Assessed Health measure is widely used both as an outcome variable in studies of social influences on health (Contoyannis \& Jones, 2004; Jürges, 2008; Kiuila \& Miesztowski, 2007) and as an explanatory variable in other studies (Disney, Emmerson, \& Wakefield, 2006; Wang, 1997). Fayers and Sprangers (2002) state that in relation to the question 'What do you think about your health in general? Very good, Good, Fair, Poor, Very Poor?' there is widespread agreement that this simple global question provides a useful summary of how patients perceive their overall health status.

Health status is highly correlated with health-care utilization. The most immediate determinant of utilization is health status (Gruber \& Kiesel, 2010). 


\subsection{Health-Care Utilization}

Numerous studies find that the health status variables are strongly associated with both visits to general practitioners (GPs) and specialists. Individuals who report a poorer health status are more likely to report greater use of physician services (Dunlop, Coyte, \& McIsaac, 2000; Laroche, 2000). Madden, Nolan, and Nolan (2005) assessed the impact of health status on health services in Ireland by looking at a range of different illnesses and find a positive relationship between each illness and the utilization of GP services, highlighting that people in poor health use GP services more. Rotermann (2006) found that in Canada, seniors who perceive their health as fair or poor are heavy users of health-care services. Similarly, Finkelstein (2001) found that the mean expenditure on physicians is substantially higher among those who reported poorer health status and that self-reported health status is significantly related to the probability of seeing a specialist.

The World Health Organization (2011) states that health is a positive concept emphasizing social and personal resources, as well as physical capacities. Rivera (2001) states that health is affected by many factors, which can be divided into four groups of variables: biological, socio-economic, lifestyle, and medical resources.

\subsection{Alcohol and Health Status}

The effects of alcohol on one's health status have been the subject of much research. In general, findings tend to be that moderate levels of alcohol consumption are beneficial toward one's health status, compared with abstaining from or consuming heavy amounts of alcohol, which has a negative effect on health status (Bau, Bau, Rosito, Manfroi, \& Fuchs, 2007; Berger et al., 1999; Klatsky, Armstrong, Friedman, \& Sidney, 2001). This gives rise to a U-shaped curve or a partial U-shaped curve referred to as a J-shaped curve, showing a reduced relative risk given 
diseases, and, in general, better health for moderate consumers of alcohol compared with abstainers or heavy drinkers (Bau et al., 2007; Berger et al., 1999; Klatsky et al. 2001). Studies looking at the relationship between alcohol consumption and specific illnesses have similar findings, in that moderate consumers of alcohol are at lower risk. Wannamethee and Shaper (1999), Rimm and Moats (2007), Bryson et al. (2006), and Klatsky et al. (2005) found this in relation to coronary heart disease. Becker et al. (1996) found this in relation to liver disease, and Berger et al. (1999), Mukamel (2007), and Klatsky et al. (2001) found this in relation to the risk of stroke. Green and Polen (2001) found that light to moderate drinkers of alcohol appear to be in better health, both mentally and physically, have better functional status, and are also more likely to engage in preventative health care services, compared with abstainers or heavy drinkers.

Similarly, in relation to alcohol consumption and the utilization of health services, findings are that male non-drinkers are more likely to use GP services. Female non-drinkers are more likely to have visited a GP when compared with moderate drinkers, but a female who has 12 drinks or more per week is more likely to have visited a GP six times or more in the previous year when compared with either non-drinkers or moderate drinkers.

Many studies have been carried out regarding the effect of alcohol consumption on income, and findings show that moderate consumers of alcohol have higher incomes (Barrett, 2002; Hamilton \& Hamilton, 1997; Ormond \& Murphy, 2016). All these studies argue that a possible explanation for this is based on the fact that medical literature states that there are health benefits to moderate levels of alcohol consumption, and referring to the Grossman (1972) theory, this would result in efficiency levels improving, hence incomes increasing. 


\section{Empirical Model}

The relationship between alcohol consumption and health status is examined. Alcohol consumption is estimated as an ordered probit model. The range of values for drinking status is divided into four intervals, each corresponding to a different category of drinker: those who never drank, non-drinkers, moderate drinkers, and heavy drinkers; the natural ordering of these four categories of drinkers seems reasonable (Harris, Ramful, \& Shao, 2006). The threshold values correspond to the cut-offs where an individual moves from reporting one category of drinker to another. Health Status and Health-Care Utilization are also estimated by ordered probit.

\subsection{Selection Bias}

In the estimation of the effect of alcohol status on health, the issue of the endogeneity and possible selection bias of alcohol consumption arises. This occurs when individuals self-select into different drinking categories, and because of this, the outcome differences may potentially be explained as a result of pre-existing differences between the groups, as opposed to the actual levels of alcohol consumed; hence, this would not be a random selection (Di Pietro \& Pedace, 2008). The error terms in both the alcohol-consumption equation and the health-status equation would then be correlated, and failure to account for non-random selection in drinking status will lead to biased estimates. Many studies into the effect of alcohol consumption on health status have not only failed to account for selection bias but also for the heterogeneity in health and drinking history among non-drinkers. These studies have combined current former drinkers and lifetime abstainers, and as a result have failed to account for the fact that former drinkers may have quit due to illness, and this in turn could increase the risk in the non-drinker category and underestimate the adverse effects of alcohol consumption on health if illnesses leading to abstention are alcohol-related (Green \& Polen, 2001). The econometric techniques used in this 
study account for possible selection bias whereby respondents self-select into drinking categories including the selection bias that may occur in relation to former drinkers.

One way of accounting for potential bias is to use the standard Heckman two-step estimation whereby selection bias can be approached as an omitted variable problem (Vella, 1998). A variety of extensions to the Heckman model (1979) has been developed for orderedchoice models. One method for addressing such selection bias is to use an ordered probit extension of the Heckman correction (Greene \& Hensher, 2010). Where the selection equation is an ordered probit, the two-step method involves estimating the participation equation by first using an ordered probit model and then computing an estimate of the inverse mills ratio for each individual in the selected sample. The inverse mills ratio is then included as an additional regressor in Step 2 of the estimation, which is estimated by ordered probit in relation to health.

\subsection{Endogeneity}

Kenkel (1995) states that in the estimation of alcohol status on health status, endogeneity could exist and should be accounted for. Both Hamilton and Hamilton (1997) and Barrett (2002) in their studies into the effect of alcohol status on earnings argue that alcohol consumption could be endogenous, and suggest that this is controlled for by treating alcohol endogenously and estimating earnings by drinker type using the two-step method proposed by Heckman or a similar method proposed by Lee.

Chiburis and Lokshin (2007) estimated the wage equations in the public, private, and informal sectors for male workers in India. Selection bias and endogeneity could occur in relation to the sectors in which the individuals work. On that basis, they carry out this estimation based on the ordered probit selection rule, where in the first step of the analysis the three categories of workers are estimated by using an ordered probit analysis. 


\subsection{Techniques used in the study of the effect of alcohol consumption on health}

\subsubsection{Alcohol-Status Equation (Step One)}

Alcohol consumption is estimated by an ordered probit model. Drinkers are divided into four categories: those who never drank, non-drinkers, moderate drinkers, and heavy drinkers. An individual's level of alcohol consumption, $c_{i}$, is dependent on a range of independent variables, $s$, each of which is thought to affect a person's level of alcohol consumption. It is assumed that the independent variables $s_{i}$ and the categorical variables $c_{i}$ are observed. In this model, individuals $i$ are sorted into $J$ categories of drinkers $1,2,3,4$, which correspond to those who never drank, nondrinkers, moderate drinkers, and heavy drinkers. Categorization is done based on an ordered probit selection rule.

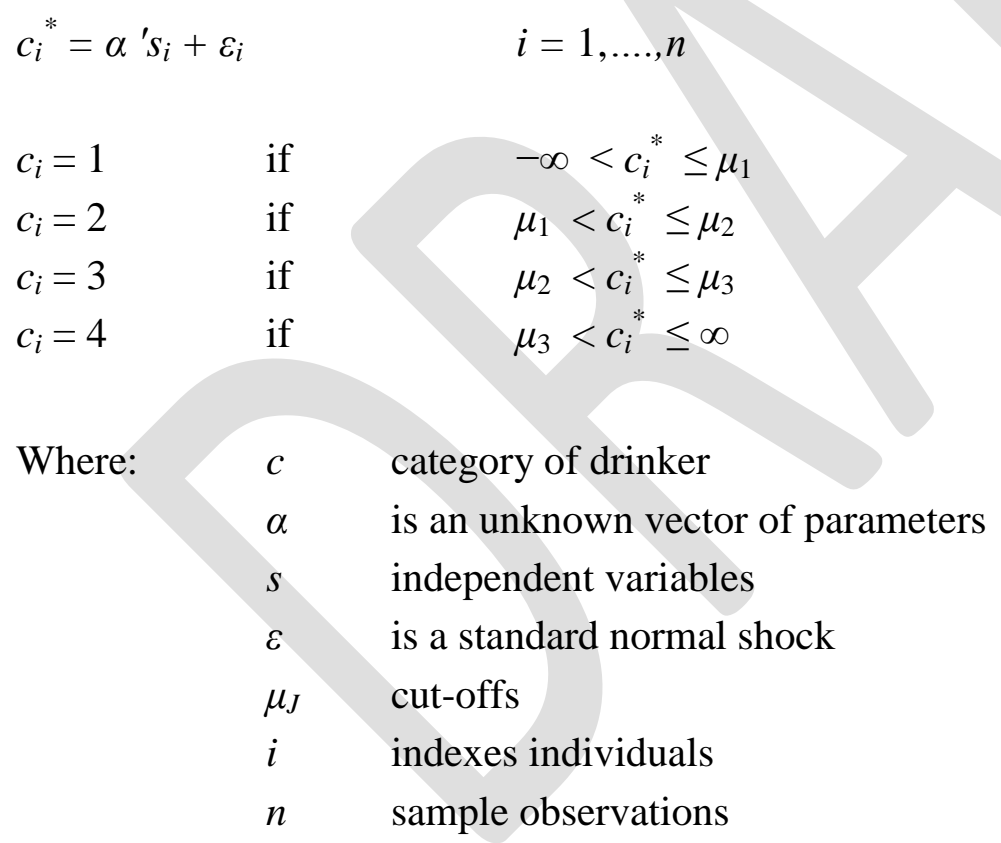

The ordered probit of $c$ on $s$ is estimated yielding consistent estimation of $\alpha$. In the ordered probit selection model it is important that there is at least one variable in the selection model $s$ that has no effect on health status, $h$, except through its effect on alcohol, $c$. Otherwise, 
the identification of the coefficient $\beta_{j}$ in the health-status equation would be weak (Chiburis \& Lokshin, 2007). In this study, the variable describing whether or not people regularly partake in church activities is used, as this variable can have an effect on alcohol consumption but not on health status. Hence, it is included in the alcohol-status equation only.

In the first step of the two-step estimation method, alcohol status is estimated by an ordered probit regression to compute estimates of $\alpha$. Level of choice is based on its $c_{i}$ value relative to the thresholds for each of the categories of drinkers, which are maximum likelihood estimates from the selection equation. An estimation of the inverse mills ratio, $\lambda_{i}$, is then computed for each individual in the sample. By estimating the inverse mills ratio, selection bias and possible endogeneity of alcohol consumption are accounted for. The equation setting out how the inverse mills ratio is derived is shown in Appendix A.

\subsubsection{Health-Status Equation (Step Two)}

In the second step of the two-step estimation, the health-status equation is estimated by an ordered probit regression, and the inverse mills ratio, $\lambda$, is also included in this equation as an additional regressor similar to that set out by Greene and Hensher (2010).

$h^{*}{ }_{i j}=x_{i} \beta_{j}+u_{i j} i=1,2 \ldots \ldots . . N \quad j=1,2,3,4$

What is observed for $\mathrm{h}$ is:

$\begin{array}{lll}h_{i}=1 & \text { if } & -\infty<h_{i}{ }^{*} \leq \mu_{1} \\ h_{i}=2 & \text { if } & \mu_{1}<h_{i}{ }^{*} \leq \mu_{2} \\ h_{i}=3 & \text { if } & \mu_{2}<h_{i}{ }^{*} \leq \mu_{3} \\ h_{i}=K & \text { if } & \mu_{\mathrm{K}-1}<h_{i}{ }^{*} \leq \infty\end{array}$

Where: $\quad h \quad$ health measure of individual

$x \quad$ vector of independent variables

$\beta \quad$ coefficients on the observable characteristics

$u_{i j} \quad$ error term

$i \quad$ indexes individuals 
$\begin{array}{ll}j & \text { indexes drinking status } \\ k & \text { categories of health status }\end{array}$

The health-status equation is estimated for each category of drinker $c$. The coefficients of $x_{i}$ depend on the category $c_{i}$. Each of the $u_{i j}$ terms are normal error terms with a variance $\sigma_{j}^{2}$. One assumes that the selection into the drinking status group is associated with health status, which means that $\varepsilon_{i}$ and each of the terms $u_{i j}$ are correlated with correlation $p_{j}$.

The Inverse Mills Ratio estimated in Step 1 is then included in the estimation of the primary equation of interest, the health-status equation, in Step 2 to account for the potential selection bias. This equation is set out in Appendix A.

By estimating the selection correction term and including this as an additional regressor in the health-status equation, selection bias and endogeneity of alcohol consumption are controlled for (Hamilton \& Hamilton, 1997).

\subsubsection{Health-Care Utilization Estimation}

Health-Care Utilization is estimated in the same manner as health status and hence controls for selection bias and endogeneity. The dependent variable 'Health-Care Utilization' is based on the number of GP consultations respondents had prior to the survey.

\section{Data and Empirical Results}

\subsection{Data}

The data to be used in this research will be taken from the 2007 Slán National Health and Lifestyle Survey, which was commissioned by the Department of Health and Children in Ireland. This survey is a cross section of the Irish adult population, aged 18 and over, and consists of 
10,364 people (62\% response rate). The selection is a random sample that is proportionately distributed across counties, localities, gender, urban/rural locations, age groups, and social classes.

The dependent variables used in this study are alcohol and health. Respondents are divided into one of four categories of drinkers: those who never drank, non-drinkers, moderate drinkers, and heavy drinkers, based on the recommendations of the Irish Health Promotion Unit within the Health Service Executive in Ireland (2008). Moderate drinkers are defined as those who had a drink in the previous month, or in the week prior to the survey, a woman who had up to 14 standard drinks or a man who had up to 21 standard drinks. Heavy drinkers are women who drank more than 14 drinks in the week prior to the survey and men who drank more than 21 drinks. Non-drinkers are those who did not have a drink in the month prior to the survey but cannot say that they never drank, and those who are categorized as having never drank are lifetime abstainers. Dummy variables for the four categories of drinkers are established.

Health Status is also treated as an ordered probit. In the Slán survey, respondents are asked to describe their health by selecting one of the following categories: Excellent, Very Good, Good, Fair, or Poor, which then results in the health status being divided into five intervals.

Similarly, Health-Care Utilization is also estimated by an ordered probit. Respondents are classified into one of five categories based on the number of times they visited a general practitioner: never visited a $\mathrm{GP}=1$, visited a GP more than 2 years ago $=2$, visited a GP between 1 and 2 years ago $=3$, visited a GP between 1 and 12 months ago $=4$, and visited a GP within the last 4 weeks $=5$.

The Slán survey includes a large number of socio-demographic characteristics, a number of which are used as explanatory variables and are shown in Table 1. The drinking-status 
equation contains all the variables that are in the health-status and health-care utilization equations. By including all of these variables in the drinking-status choice equation, the effect of health status on drinking behavior is controlled for, which is similar to what Hamilton and Hamilton (1997) and Barrett (2002) did in their studies on the effect of alcohol status on income.

Table 1. Descriptive statistics

\begin{tabular}{|c|c|c|c|c|c|}
\hline Variable Definitions & $\begin{array}{c}\text { Drinking } \\
\text { Status } \\
\text { Equation }\end{array}$ & $\begin{array}{c}\text { Health } \\
\text { Status } \\
\text { Equation }\end{array}$ & $\begin{array}{c}\text { Health Care } \\
\text { Utilization }\end{array}$ & Mean & $\begin{array}{l}\text { Standard } \\
\text { Deviation }\end{array}$ \\
\hline \multicolumn{6}{|l|}{ Dependent Variables } \\
\hline $\begin{array}{l}\text { Alcohol Status: Never Drank }=1 ; \text { Non Drinkers }=2, \\
\text { Moderate Drinkers }=3, \text { Heavy Drinkers }=4\end{array}$ & & & & 1.796 & .545 \\
\hline $\begin{array}{l}\text { Health Status }=\text { Self-Assessed Health Status }(1=\text { poor } \\
\text { health status to } 5=\text { excellent health status })\end{array}$ & & & & 3.61 & 1.03 \\
\hline $\begin{array}{l}\text { Health-Care Utilization }=\text { Last time an individual visited a } \\
\text { GP }(1=\text { never and } 5=\text { in the last } 4 \text { weeks })\end{array}$ & & & & 3.94 & 0.95 \\
\hline \multicolumn{6}{|l|}{ Independent Variables } \\
\hline Males $=$ Individuals who are male, $0=$ female & $\mathrm{X}$ & $\mathrm{X}$ & $\mathrm{X}$ & 0.427 & 0.495 \\
\hline Age $18-29=$ those who are aged 18 to $29,0=$ otherwise & $\mathrm{X}$ & $\mathrm{X}$ & $\mathrm{X}$ & 0.174 & 0.379 \\
\hline Age $30-39=$ those who are aged 30 to $39,0=$ otherwise & $\mathrm{X}$ & $\mathrm{X}$ & $\mathrm{X}$ & 0.219 & 0.414 \\
\hline Age $40-49=$ those who are aged 40 to $49,0=$ otherwise & $\mathrm{X}$ & $\mathrm{X}$ & $\mathrm{X}$ & 0.191 & 0.393 \\
\hline Age $50-59=$ those who are aged 50 to $59,0=$ otherwise & $\mathrm{X}$ & $\mathrm{X}$ & $\mathrm{X}$ & 0.154 & 0.361 \\
\hline Age $60-69=$ those who are aged 60 to $69,0=$ otherwise $*$ & $\mathrm{X}$ & $\mathrm{X}$ & $\mathrm{X}$ & 0.130 & 0.336 \\
\hline Age 70 plus $=$ those who are aged 70 plus, $0=$ otherwise & $\mathrm{X}$ & $\mathrm{X}$ & $\mathrm{X}$ & 0.132 & 0.338 \\
\hline Married $=$ Individuals who are married, $0=$ otherwise & $\mathrm{X}$ & $\mathrm{X}$ & $\mathrm{X}$ & 0.506 & 0.500 \\
\hline Widowed $=$ Individuals who are widowed, $0=$ otherwise & $\mathrm{X}$ & $\mathrm{X}$ & $\mathrm{X}$ & 0.087 & 0.281 \\
\hline $\begin{array}{l}\text { Sep/Div = Individuals who are separated or divorced, } \\
0=\text { otherwise }\end{array}$ & $\mathrm{X}$ & $\mathrm{X}$ & $\mathrm{X}$ & 0.063 & 0.243 \\
\hline $\begin{array}{l}\text { Single/Never Married = Individuals who are single/never } \\
\text { married, } 0=\text { otherwise }\end{array}$ & $\mathrm{X}$ & $\mathrm{X}$ & $\mathrm{X}$ & 0.280 & 0.449 \\
\hline Cohabiting $=$ Individuals who are cohabiting, $0=$ otherwise $^{*}$ & $\mathrm{X}$ & $\mathrm{X}$ & $\mathrm{X}$ & 0.062 & 0.242 \\
\hline $\begin{array}{l}\text { Ed primary }=\text { Individuals who have primary school } \\
\text { education only, } 0=\text { otherwise } *\end{array}$ & $\mathrm{X}$ & $\mathrm{X}$ & $\mathrm{X}$ & 0.174 & 0.379 \\
\hline $\begin{array}{l}\text { Educ. Secondary = Individuals who have completed } \\
\text { secondary education only, } 0=\text { otherwise }\end{array}$ & $\mathrm{X}$ & $\mathrm{X}$ & $\mathrm{X}$ & 0.441 & 0.497 \\
\hline $\begin{array}{l}\text { Educ. Diploma }=\text { Individuals who have a diploma or } \\
\text { certificate, } 0=\text { otherwise }\end{array}$ & $\mathrm{X}$ & $\mathrm{X}$ & $\mathrm{X}$ & 0.185 & 0.388 \\
\hline
\end{tabular}


Table 1 continued. Descriptive statistics

\begin{tabular}{|c|c|c|c|c|c|}
\hline Variable Definitions & $\begin{array}{l}\text { Drinking } \\
\text { Status } \\
\text { Equation }\end{array}$ & $\begin{array}{c}\text { Health } \\
\text { Status } \\
\text { Equation } \\
\end{array}$ & $\begin{array}{c}\text { Health } \\
\text { Care } \\
\text { Utilization } \\
\end{array}$ & Mean & $\begin{array}{l}\text { Standard } \\
\text { Deviation }\end{array}$ \\
\hline $\begin{array}{l}\text { Educ. Primary Degree = Individuals who have a primary } \\
\text { degree, } 0=\text { otherwise }\end{array}$ & $\mathrm{X}$ & $\mathrm{X}$ & $\mathrm{X}$ & 0.104 & 0.306 \\
\hline $\begin{array}{l}\text { Educ. Post Graduate }=\text { Individuals who have completed a } \\
\text { postgraduate/higher degree, } 0=\text { otherwise }\end{array}$ & $X$ & $\mathrm{X}$ & $X$ & 0.096 & 0.296 \\
\hline $\begin{array}{l}\text { Employee }=\text { those whose current employment situation is an } \\
\text { employee at work, } 0=\text { otherwise }\end{array}$ & $\mathrm{X}$ & $X$ & $X$ & 0.458 & 0.498 \\
\hline $\begin{array}{l}\text { Self-employed }=\text { those whose current employment situation } \\
\text { is self-employed or in farming, } 0=\text { otherwise }\end{array}$ & $\mathrm{X}$ & $\mathrm{X}$ & $X$ & 0.115 & 0.320 \\
\hline $\begin{array}{l}\text { Disability }=\text { those whose current employment situation is } \\
\text { unable to work owing to permanent sickness/disability, } \\
0=\text { otherwise* }\end{array}$ & $\mathrm{X}$ & $\mathrm{X}$ & $\mathrm{X}$ & 0.038 & 0.192 \\
\hline $\begin{array}{l}\text { State Training/Student }=\text { those who are students or on a state } \\
\text { training program, } 0=\text { otherwise }\end{array}$ & $X$ & $X$ & $\mathrm{X}$ & 0.037 & 0.189 \\
\hline $\begin{array}{l}\text { Unemployed }=\text { those whose current employment situation is } \\
\text { unemployed, } 0=\text { otherwise }\end{array}$ & $\mathrm{X}$ & $\mathrm{X}$ & $\mathrm{X}$ & 0.030 & 0.170 \\
\hline $\begin{array}{l}\text { Homemaker }=\text { those whose current employment situation is } \\
\text { Homemaker, } 0=\text { otherwise }\end{array}$ & $\mathrm{X}$ & $\mathrm{X}$ & $X$ & 0.140 & 0.347 \\
\hline $\begin{array}{l}\text { Retired }=\text { those whose current employment situation is } \\
\text { wholly retired, } 0=\text { otherwise }\end{array}$ & $X$ & $X$ & $\mathrm{X}$ & 0.169 & 0.375 \\
\hline $\begin{array}{l}\text { Other }=\text { those whose current employment situation is } \\
\text { classified as other, } 0=\text { otherwise }\end{array}$ & $\mathrm{X}$ & $X$ & $\mathrm{X}$ & 0.010 & 0.097 \\
\hline $\begin{array}{l}\text { Race White }=\text { those who are white or white Irish, } \\
0=\text { otherwise }\end{array}$ & $\mathrm{X}$ & $\mathrm{X}$ & $\mathrm{X}$ & 0.970 & 0.169 \\
\hline $\begin{array}{l}\text { Race Black = those who are black or white Irish, } \\
0=\text { otherwise }\end{array}$ & $\mathrm{X}$ & $\mathrm{X}$ & $\mathrm{X}$ & 0.008 & 0.089 \\
\hline $\begin{array}{l}\text { Race Asian = those who are Asian or Asian Irish, } \\
0=\text { otherwise }\end{array}$ & $\mathrm{X}$ & $X$ & $\mathrm{X}$ & 0.008 & 0.089 \\
\hline $\begin{array}{l}\text { Race Other }=\text { those who are from another or a mixed } \\
\text { background, } 0=\text { otherwise* }\end{array}$ & $\mathrm{X}$ & $\mathrm{X}$ & $X$ & 0.006 & 0.077 \\
\hline Log income is the log of household income & & & $\mathrm{X}$ & 6.398 & .713 \\
\hline Total in hh $=$ total number of people in household & $\mathrm{X}$ & $\mathrm{X}$ & $\mathrm{X}$ & 5.811 & 3.189 \\
\hline $\begin{array}{l}\text { Open country = individuals living in the open country, } \\
0=\text { otherwise* }\end{array}$ & $\mathrm{X}$ & $X$ & $X$ & 0.309 & 0.462 \\
\hline Village $=$ individuals living in a village, $0=$ otherwise & $X$ & $X$ & $X$ & 0.107 & 0.309 \\
\hline Town $=$ individuals living in a town, $0=$ otherwise & $X$ & $X$ & $X$ & 0.243 & 0.429 \\
\hline $\begin{array}{l}\text { City other than Dublin = individuals living in a city other } \\
\text { than Dublin, } 0=\text { otherwise }\end{array}$ & $X$ & $X$ & $X$ & 0.106 & 0.307 \\
\hline
\end{tabular}

\subsection{Results}

In the first step of the two-step model, alcohol status is estimated by an ordered probit generating the Inverse Mills Ratio. Results from both alcohol status regressions in the estimation of health status and health-care utilization are set out in the Appendix. The coefficients listed indicate the effect each variable has on the probability of an individual being in a higher drinking 
category. The corresponding $z$ statistics, testing the null hypothesis of statistical significance of the variables in the alcohol-status equation, are also given along with the marginal effects.

\subsubsection{Results from the estimation of Health Status}

Results for the selection-corrected health-status equations estimated in Step 2 are presented in Table 2.

Table 2. Results-ordered probit model estimating health status

\begin{tabular}{|c|c|c|c|c|c|c|c|c|}
\hline & \multicolumn{2}{|c|}{ Never Drank } & \multicolumn{2}{|c|}{ Non-Drinkers } & \multicolumn{2}{|c|}{ Moderate Drinkers } & \multicolumn{2}{|c|}{ Heavy Drinkers } \\
\hline & Coefficient & $z$ stat & Coefficient & $z$ stat & Coefficient & $z$ stat & Coefficient & $z$ stat \\
\hline Educ. Secondary & 0.467 & $4.22 *$ & 0.148 & 1.53 & 0.222 & $3.78 *$ & 0.307 & 1.07 \\
\hline Educ. Diploma & 0.416 & $2.68 *$ & 0.413 & $3.12 *$ & 0.234 & $3.51 *$ & 0.259 & 0.74 \\
\hline Educ Prim Dgre & 0.528 & $2.69 *$ & 0.524 & $3.18 *$ & 0.338 & $4.57 *$ & 0.273 & 0.72 \\
\hline Educ Post Grad & 0.377 & $2.14 * *$ & 0.314 & $2.02 * *$ & 0.393 & $5.17 *$ & 0.170 & 0.5 \\
\hline Age18-29 & 1.516 & $5.84 *$ & 0.805 & $4.29 *$ & 0.429 & $5.2 *$ & 0.737 & 1.4 \\
\hline Age 30-39 & 0.941 & $5.06^{*}$ & 0.584 & $3.97 *$ & 0.328 & $4.63 *$ & 0.826 & 2.27 \\
\hline Age 40-49 & 0.661 & $3.72 *$ & 0.516 & $3.5^{*}$ & 0.253 & $3.56^{*}$ & 0.832 & 2.28 \\
\hline Age 50-59 & 0.568 & $3.87 *$ & 0.057 & 0.44 & 0.005 & 0.07 & 0.426 & 1.27 \\
\hline Age 70plus & -0.580 & $-3.48 *$ & -0.249 & -1.73 & 0.080 & 0.86 & -0.201 & -0.4 \\
\hline Employee & 1.620 & $7.76^{*}$ & 1.135 & $6.8^{*}$ & 1.140 & $11.26^{*}$ & 1.393 & $3.53 *$ \\
\hline Self employed & 1.262 & $5.8 *$ & 1.181 & $6.48 *$ & 1.185 & $10.92 *$ & 1.187 & $2.99 *$ \\
\hline $\begin{array}{l}\text { State Training or } \\
\text { Student }\end{array}$ & 1.826 & $5.48 *$ & 1.031 & $4.11 *$ & 1.131 & $8.9^{*}$ & 1.341 & $2.26 * *$ \\
\hline Unemployed & 1.284 & $4.84 *$ & 0.916 & $3.61 *$ & 1.285 & $9.19 *$ & 1.214 & $2.84 *$ \\
\hline Homemaker & 1.143 & $6.38 *$ & 0.932 & $5.32 *$ & 1.081 & $10.33^{*}$ & 0.810 & $2.17 * *$ \\
\hline Retired & 1.244 & $6.28 *$ & 0.797 & $4.51 *$ & 0.873 & $7.59 *$ & 1.253 & $2.63 *$ \\
\hline Other & 0.954 & $3.52 *$ & 1.009 & $3.04 *$ & 1.387 & $7.73 *$ & -0.755 & -1.26 \\
\hline Log income & 0.332 & $3.28 *$ & 0.077 & 0.91 & 0.120 & $3.74 *$ & 0.246 & 1.21 \\
\hline
\end{tabular}


Table 2 continued. Results-ordered probit model estimating health status

\begin{tabular}{|c|c|c|c|c|c|c|c|c|}
\hline & \multicolumn{2}{|c|}{ Never Drank } & \multicolumn{2}{|c|}{ Non-Drinkers } & \multicolumn{2}{|c|}{ Moderate Drinkers } & \multicolumn{2}{|c|}{ Heavy Drinkers } \\
\hline & Coefficient & $z$ stat & Coefficient & $z$ stat & Coefficient & $z$ stat & Coefficient & $z$ stat \\
\hline Race White & 0.260 & 1.1 & 0.155 & 0.55 & -0.076 & -0.61 & 0.563 & 1.13 \\
\hline Race Black & -0.606 & -1.68 & 0.497 & 1.18 & -0.215 & -0.9 & \multicolumn{2}{|c|}{ Omitted } \\
\hline Race Asian & -1.784 & $-3.9 *$ & -0.151 & -0.31 & -0.108 & -0.4 & -0.377 & -0.38 \\
\hline Male & 0.453 & $2.55 * *$ & -0.020 & -0.19 & -0.137 & $-3.69 *$ & 0.057 & 0.16 \\
\hline Married & -0.152 & -0.86 & 0.360 & $2.19 * *$ & 0.119 & 1.92 & -0.029 & -0.15 \\
\hline Widowed & -0.030 & -0.15 & 0.594 & $2.95 *$ & 0.036 & 0.4 & 0.026 & 0.07 \\
\hline Separated/ divorced & 0.020 & 0.08 & 0.370 & 1.89 & 0.116 & 1.38 & -0.077 & -0.3 \\
\hline $\begin{array}{l}\text { Single/never } \\
\text { married }\end{array}$ & -0.093 & -0.53 & 0.232 & 1.41 & 0.105 & 1.74 & -0.120 & -0.6 \\
\hline Total in h.hold & -0.013 & -1.04 & 0.016 & 1.2 & -0.009 & -1.56 & 0.015 & 0.83 \\
\hline Village & 0.070 & 0.56 & -0.043 & -0.39 & -0.043 & -0.81 & -0.019 & -0.08 \\
\hline Town & -0.064 & -0.63 & 0.110 & 1.16 & -0.096 & $-2.34 * *$ & 0.020 & 0.1 \\
\hline City not Dublin & 0.451 & 2.29 & 0.128 & 0.9 & 0.058 & 1.05 & 0.207 & 0.61 \\
\hline Dublin city & 0.270 & 1.84 & 0.073 & 0.67 & 0.007 & 0.17 & 0.078 & 0.27 \\
\hline Smoker & 0.214 & 1.18 & -0.133 & -1.17 & -0.279 & $-7.37 *$ & -0.040 & -0.11 \\
\hline Weight right & 0.440 & $3.11 *$ & 0.004 & 0.02 & -0.042 & -0.57 & 0.132 & 0.43 \\
\hline Weight too heavy & 0.240 & 1.45 & -0.388 & $-2.29 * *$ & -0.345 & $-4.5^{*}$ & -0.161 & -0.43 \\
\hline Weight too light & 0.026 & 0.13 & -0.796 & $-3.41 *$ & -0.307 & $-2.8^{*}$ & -0.287 & -0.76 \\
\hline $\begin{array}{l}\text { Medical Card } \\
\text { Holder }\end{array}$ & -0.130 & -1.49 & -0.214 & $-2.36 * *$ & -0.223 & $-5.16^{*}$ & 0.188 & 1.26 \\
\hline Health Insurance & 0.335 & $-4.29 *$ & 0.069 & 0.8 & 0.087 & $2.44 * *$ & 0.143 & 1.05 \\
\hline Correction sel. & -1.769 & $-3.04 *$ & -0.492 & -0.99 & -0.399 & -1.63 & 0.852 & 0.69 \\
\hline Cut Off 1 & 0.199 & & -0.425 & & -0.680 & & 3.537 & \\
\hline Cut Off 2 & 1.217 & & 0.561 & & 0.297 & & 4.673 & \\
\hline Cut Off 3 & 2.218 & & 1.569 & & 1.437 & & 5.861 & \\
\hline Cut Off 4 & 3.289 & & 2.681 & & 2.566 & & 6.880 & \\
\hline
\end{tabular}


Table 2 continued. Results-ordered probit model estimating health status

\begin{tabular}{|l|l|l|l|}
\hline Never Drank & Non-Drinkers & Moderate Drinkers & Heavy Drinkers \\
Number of obs $=1305$ & Number of obs $=1067$ & Number of obs $=5596$ & Number of obs $=551$ \\
Wald chi2(37) $=435.11$ & Wald chi2 $(37)=358.28$ & Wald chi2 $(37)=1098.49$ & Wald chi2(35) $=132.65$ \\
Prob $>$ chi2 $=0.0000$ & Prob $>$ chi2 $=0.0000$ & Prob $>$ chi2 $=0.0000$ & Prob $>$ chi2 $=0.0000$ \\
Pseudo $R^{2}=0.1112$ & Pseudo $R^{2}=0.1306$ & Pseudo $R^{2}=0.0801$ & Pseudo $R^{2}=.0745$ \\
Log Pseudolikelihood & Log Pseudolikelihood & Log Pseudolikelihood & Log Pseudolikelihood \\
$=-1719.7519$ & $=-1393.208$ & $=-6950.4236$ & $=-695.97783$ \\
\hline
\end{tabular}

* indicates significance at $1 \%$ and $5 \%$ level

Note: Physically active dropped due to multicolinearity.

Race Black for heavy drinkers dropped due to multicolinearity.

Looking at the different categories of drinkers, 5,596 respondents are classified as moderate drinkers, 1,305 as never having drank, 1,067as non-drinkers, and 551 as heavy drinkers. The Wald Test shows that the models are statistically significant and rejects the null hypothesis that coefficients of the variables are equal to zero.

Education is a very significant variable in terms of health status for those who never drank, non-drinkers, and moderate drinkers. Individuals in these three categories with a thirdlevel education, either a higher diploma, primary degree or a postgraduate degree, are more likely to report having a better health status compared with those who have a second level of education only. Previous studies also find that education strongly contributes to better health (Behrman \& Wolfe, 1989; Berger \& Leigh, 1989; Gilleskie \& Harrison, 1998; Hartog \& Oosterbeek, 1998; Kenkel, 1991, 1995; Leigh, 1998).

This study finds that all ages are significant in terms of the health status of those who never drank. In particular, individuals in this category who are aged 18-29 years are very likely to report excellent health status, and those aged 70 years or over are $4.4 \%$ more likely to report 
poorer health status. This is similar to previous studies by Lin (2008), Wilson, Rosenberg, \& Abonyi, (2011), Yen, Shaw, \& Yuan (2010) which all find that older people report poorer health. Non-drinkers and moderate drinkers aged 18-49 years are most likely to report a higher category of Health Status. For heavy drinkers, age is not a significant variable.

The employment status variables are in general statistically significant in the determination of health status across all categories of drinkers. All variables describing employment status are positively correlated with health status holding other variables constant for all categories of drinkers.

Log of income is a very significant positive variable in the health-status equation for both those who never drank and moderate drinkers. Particularly in relation to those who never drank, they are likely to report a higher category of self-assessed health associated with higher income. These findings are generally consistent with previous findings showing that those with lower income also reported a lower self-reported health (Buckley, Denton, Robb, \& Spencer, 2004; Yen et al., 2010). Tremblay, Ross, \& Berthelot (2002) show this is also the case in relation to household income.

Race is not significant in the determination of health status of non-drinkers, moderate drinkers, and heavy drinkers. For those who never drank, the only race variable that is significant is that describing those of Asian race, and for this variable the coefficient is negative, showing that those of Asian race who never drank are $39.8 \%$ more likely to report a poor category of selfassessed health. Results from previous studies vary in relation to the effect of race on health status. Many studies show that the black race tends to have poorer health when compared to other races (Thompson, 2011). In contrast, Habicht and Kunst (2005) found that ethnic differences were generally very small, with no consistently higher use by one group. 
Gender is a significant determinant of health status of those who never drank and moderate drinkers. Males who never drank and female moderate drinkers are more likely to report a higher category of health status. Male non-drinkers are just over $2 \%$ less likely than females to report poor health status. Lin (2008), Kwan (2010), Liu (2008), Lahelma, Markikainen, Rahkonen, \& Silventoinen (1999), and Lianga, Bennett, Sugisawac, Kobayashid, \& Fukayad (2003) all found that males report better health than females.

In terms of marital status, non-drinkers who are married or widowed are likely to report a higher health status, which is in contrast to previous findings such as those of Wilson et al. (2011). For both moderate and heavy drinkers as well as those who never drank, marital status is not a significant determinant of health status. Numerous studies found that married individuals are healthier than single individuals (Rosengren, Wedel, \& Wilhelmsen, 1989; Zick \& Smith, 1991). Number of people living in the household is not significant for any category of drinker.

Where one lives can also affect one's health status. In this study, it appears that the variables describing where respondents live does not have a significant impact on health status. Findings from other studies show that the health status varies across the urban/rural divide for the different drinking categories. Findings from previous studies are varied. Wilson et al. (2011) showed that those living in rural areas are more likely to report fair/poor health than those living in urban areas, whereas contrary to this, Lin (2008) showed that people living in urban areas in Taiwan are more likely to report poorer health.

In terms of the Lifestyle variables, smoking is only significant in the health-status equation for moderate drinkers. Moderate drinkers who smoke are likely to report being in the lower categories of health status, i.e., they are $0.7 \%$ more likely to report poor health. Previous literature finds that smoking has a negative effect on health status (Ho, Lam, Fielding, \& Janus, 
2003; Holman et al., 1988; Manning, Keeler, Newhouse, Sloss, \& Wasserman, 1991; Mathers \& Loncar, 2006; WHO, 2009; Yen et al., 2010).

The variable describing whether respondents are physically active is dropped for all categories of drinkers due to colinearity. Those who never drank and who describe their weight as 'just right' tend to report higher categories of health status and are $2.9 \%$ less likely to report poor health. Moderate drinkers who describe their weight as 'too heavy' or 'too light' tend to report a lower category of health status and are approximately $1 \%$ more likely to report poor health. Both these variables are significant in the health-status equation of moderate drinkers. Previous findings were similar and found that those who are overweight tend to have a poorer health status, particularly in relation to males (Lin, 2008). Contoyannis and Jones (2004) also found that those who are not obese have a higher reporting of excellent or good health.

Individuals with a medical card, which is a means-tested entitlement to the majority of health services free of charge, is significant for non-drinkers and moderate drinkers. Both nondrinkers and moderate drinkers who have a medical card are likely to report having lower categories of health. Similarly, health insurance is also significant for those who never drank and moderate drinkers. Moderate drinkers with health insurance are likely to report having poorer health, while those who never drank are $2 \%$ less likely to report poor health. Harmon and Nolan (2001) and Hurd and McGarry (1997) found that those in better health are more likely to be insured, or at least there is no evidence for adverse selection. Höfter (2006) also finds that people with private health insurance tend to be healthier individuals.

The selection correction terms, inverse mills ratio, are significant only for those who never drank but not significant for the other three categories of drinkers. In relation to those who never drank, the coefficient is negative, which indicates that individuals who self-select into 
being a lifetime abstainer are $10.8 \%$ more likely to have poorer health status on average than an individual with identical observable characteristics drawn at random would have as a nondrinker. Individuals who decide or have a preference to be a non-drinker also tend to be individuals with a poor health status.

\subsubsection{Overall Health Status by Drinker Type}

In relation to all four categories of drinkers, the majority of respondents report good or very good health status. Table 3 shows the percent breakdown of the self-assessed health for each category of drinker. 
Table 3. Results of health status by drinker type

\begin{tabular}{|c|c|}
\hline \multicolumn{2}{|c|}{ Never Drank } \\
\hline Poor Health Status & $5.31 \%$ \\
\hline Fair Health Status & $16.99 \%$ \\
\hline Good Health Status & $30.54 \%$ \\
\hline Very Good Health Status & $30.26 \%$ \\
\hline Excellent Health Status & $16.91 \%$ \\
\hline \multicolumn{2}{|c|}{ Non Drinkers } \\
\hline Poor Health Status & $6.97 \%$ \\
\hline Fair Health Status & $17.14 \%$ \\
\hline Good Health Status & $29.69 \%$ \\
\hline Very Good Health Status & $30.30 \%$ \\
\hline Excellent Health Status & $15.90 \%$ \\
\hline \multicolumn{2}{|c|}{ Moderate Drinkers } \\
\hline Poor Health Status & $1.89 \%$ \\
\hline Fair Health Status & $8.40 \%$ \\
\hline Good Health Status & $28.73 \%$ \\
\hline Very Good Health Status & $37.78 \%$ \\
\hline Excellent Health Status & $23.19 \%$ \\
\hline \multicolumn{2}{|c|}{ Heavy Drinkers } \\
\hline Poor Health Status & $1.71 \%$ \\
\hline Fair Health Status & $9.85 \%$ \\
\hline Good Health Status & $32.14 \%$ \\
\hline Very Good Health Status & $34.23 \%$ \\
\hline Excellent Health Status & $22.07 \%$ \\
\hline
\end{tabular}


While the majority of respondents report good or very good health in each category of drinker, this percentage is higher for both moderate and heavy drinkers compared with nondrinkers and those who never drank.

Looking at those who report excellent health across all four categories, a higher percentage of moderate drinkers, $23.19 \%$, report excellent health compared with $22.07 \%$ of heavy drinkers, $15.9 \%$ of non-drinkers, and $16.91 \%$ of those who never drank.

Combining respondents who report good, very good, and excellent health, those who never drank are at $77.71 \%$, non-drinkers are at $75.89 \%$, moderate drinkers are at $89.7 \%$, and heavy drinkers are at $88.44 \%$.

Percentage of respondents who report poor and fair health status is significantly different between the different groups. $22.29 \%$ of those who never drank report having poor or fair health, $24.11 \%$ of non-drinkers, $10.3 \%$ of moderate drinkers, and $11.56 \%$ of heavy drinkers.

These findings show that moderate drinkers report having the best health status compared with all other categories of drinkers, with more moderate drinkers reporting having excellent health status. Similarly, by combining good, very good, and excellent health status, more moderate drinkers again report being in this group. Fewer moderate drinkers report having poor/fair health status compared with the other three categories of drinkers.

Looking at non-drinkers and those who never drank (abstainers), the percentage reporting excellent health is substantially less and those reporting poor and fair health is substantially more when compared to moderate and heavy drinkers.

Heavy drinkers do report a better health status compared with non-drinkers and those who never drank. However, they do not enjoy a health status as good as that of moderate drinkers. These results are also depicted in Fig. 1. 


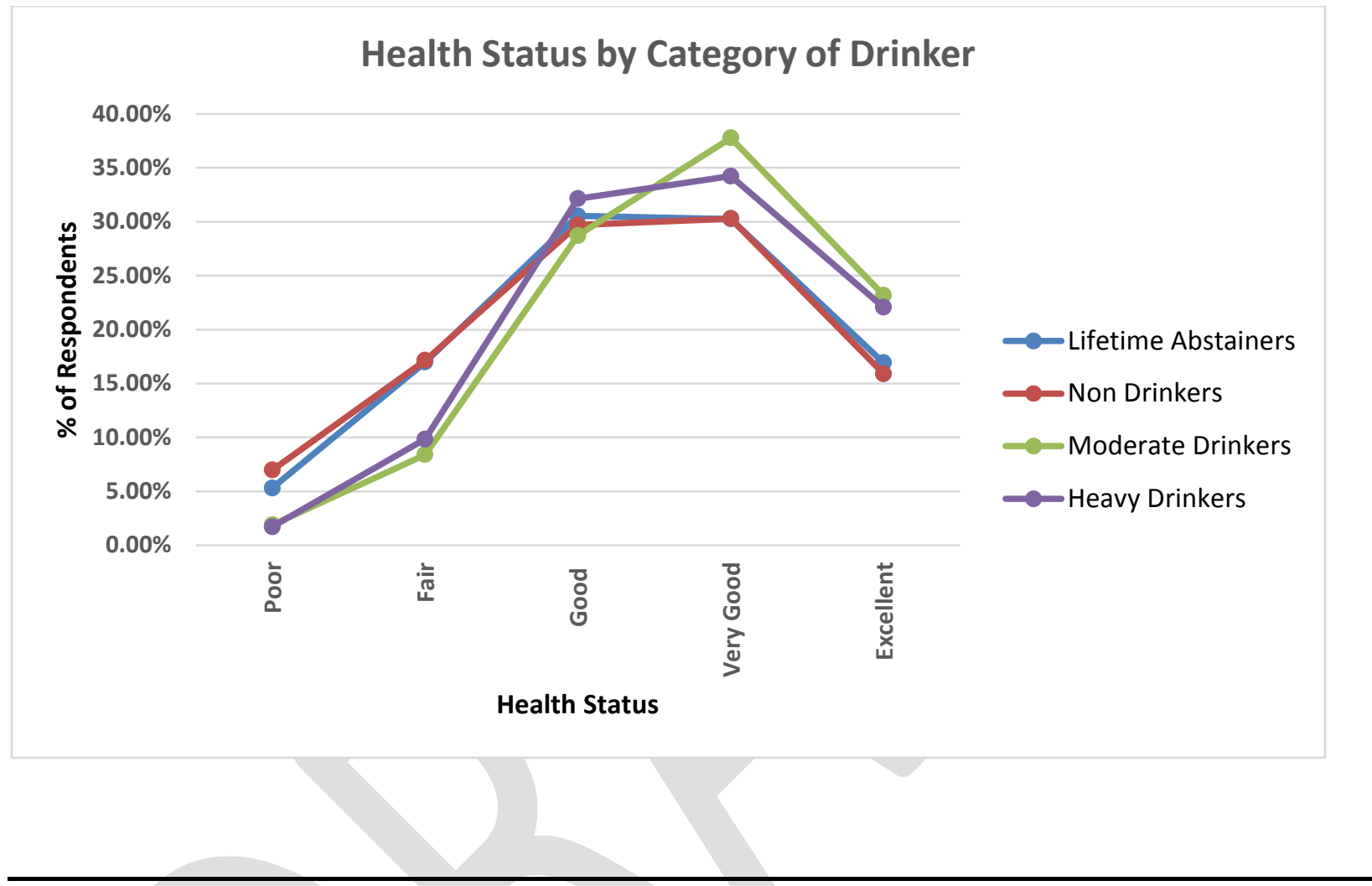

In general, these findings show that the health status of non-drinkers, those who never drank, and heavy drinkers is not as good as that of moderate drinkers. These findings are similar to the findings of other studies, which show that moderate consumers of alcohol tend to have better health (Bau et al., 2007; Berger et al., 1999; Klatsky et al., 2001). 


\subsubsection{Health-Care Utilization - Consultations with the GP}

Health-Care Utilization is estimated by an ordered probit accounting for the potential selection bias of drinking status by including the selection correction terms from the alcohol status estimation. Health-Care Utilization is measured by looking at the number of times a person consulted with a general practitioner.

Results from the estimation of health care utilization are set out in the Appendix.

The results showing the level of GP consultation by the four drinker types are set out in Table 4 .

Table 4. Results of GP consultations by drinker type

\begin{tabular}{|c|c|c|c|c|}
\hline Last time consulted GP & Never Drank & Non-Drinker & Moderate Drinker & Heavy Drinker \\
\hline Never & $2 \%$ & $1 \%$ & $1 \%$ & $1 \%$ \\
\hline more than 2 years ago & $9 \%$ & $8 \%$ & $10 \%$ & $15 \%$ \\
\hline 1-2 years ago & $8 \%$ & $9 \%$ & $13 \%$ & $15 \%$ \\
\hline between 1 and 12 months & $47 \%$ & $42 \%$ & $51 \%$ & $46 \%$ \\
\hline in last 4 weeks & $35 \%$ & $41 \%$ & $25 \%$ & $23 \%$ \\
\hline
\end{tabular}

Results show that more non-drinkers and those who never drank consulted a GP in the 4 weeks prior to the survey than either moderate or heavy drinkers. Moderate drinkers utilized the GP slightly more than heavy drinkers in the 4 weeks prior to the survey.

In the year prior to the survey, non-drinkers and those who never drank utilized GP services the most, with $82 \%$ of those who never drank and $83 \%$ of non-drinkers reporting having visited a GP in this period, compared with $76 \%$ of moderate drinkers and $70 \%$ of heavy drinkers. In looking at those who visited a GP one year ago or more, heavy drinkers had the highest percentage of visits. 


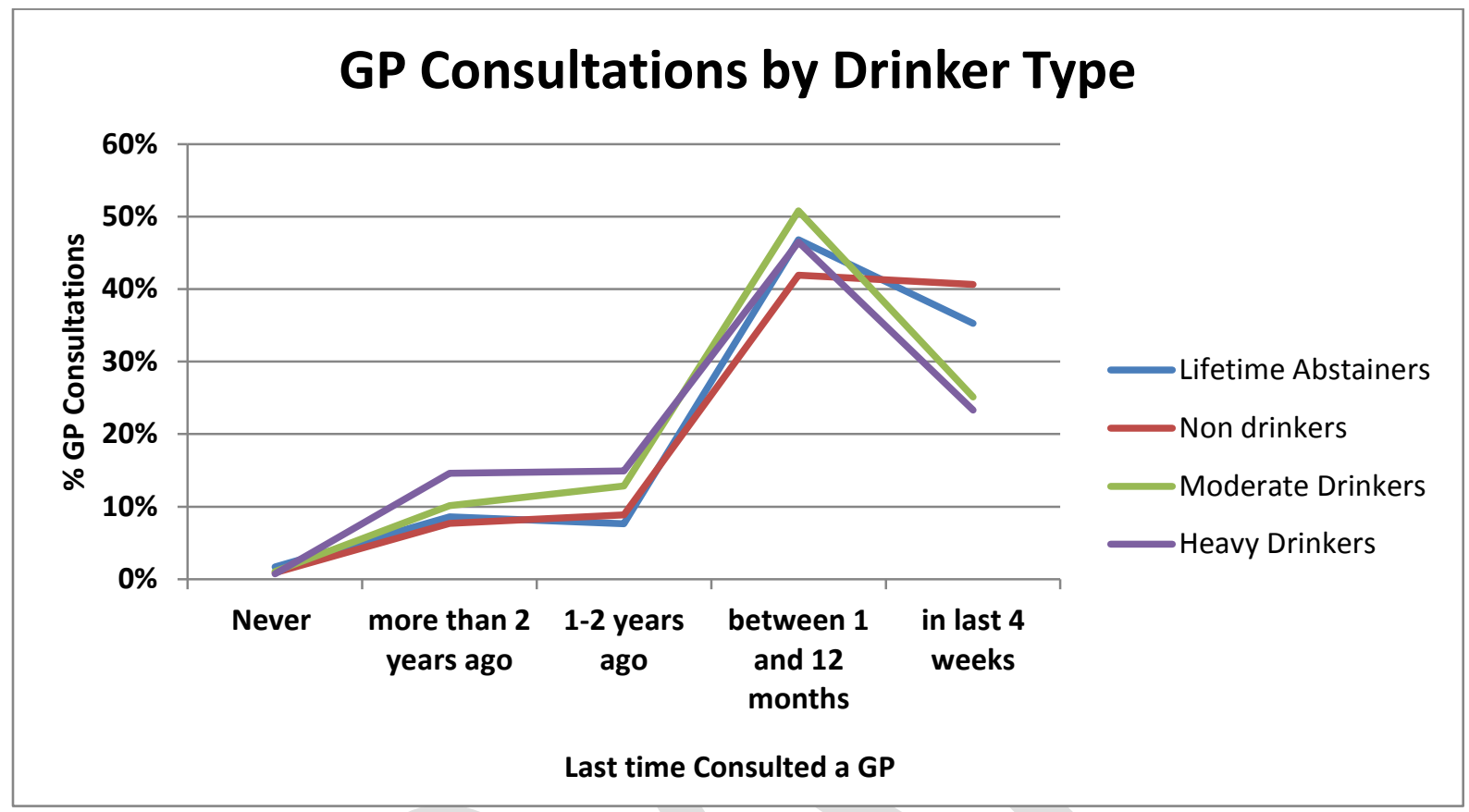

Generally, usage of GP Services is very similar across drinker types. However, more nondrinkers and those who never drank visited a GP in the 4 weeks prior to the survey compared with both moderate and heavy drinkers. This is similar to the findings of Dunlop et al. (2000), who found that male non-drinkers visit a GP more than drinkers, and female non-drinkers visit a GP more than those who drink moderately but not more than those who are heavy drinkers. These findings are in agreement with the findings on health status, whereby more non-drinkers tend to report poorer health. However, in relation to health status, moderate drinkers reported having better health status compared with heavy drinkers, yet in looking at the number of visits 
to a GP, heavy drinkers visited a GP fewer times in the year prior to the survey compared with moderate drinkers.

\subsection{Post-Estimation Diagnostics in both the Estimation of Health Status and Health-Care Utilization}

\subsubsection{Testing the Specification of the Model}

The significance of each of the variables is assessed using the $z$ statistic along with the Likelihood Ratio Test to evaluate the variables in the model. The Wald Test shows that the models are statistically significant. Due to the lack of suitable instruments for the potentially endogenous lifestyle variables smoking, physical activity, and weight, this study was unable to account for this possible endogeneity. Similar to Kenkel (1995), the alcohol-status equation and the health-status equations are estimated omitting these, showing no difference to the results.

Establishing the direction of causality between health and income also poses significant problems (Kiuila \& Mieszkowski, 2007). Being unable to instrument for income due to the lack of instrumental variables, including the variables describing the respondent's employment status (Kiuila \& Mieszkowski, 2007) and education (Contoyannis \& Jones, 2004) allows for only partial control for the possible effect of poor health on low income.

The null hypothesis that the cut-offs are equal to each other is tested in both the alcohol status and health status-ordered probit models. The null hypothesis is rejected in all cases, showing that the cut-offs are not equal to each other and hence that categories should not be merged. 


\section{Conclusion}

This paper presents an empirical study of the effect of alcohol consumption on individual health status and health-care utilization in Ireland. The endogenous relationship between alcohol and health is accounted for, including the possible heterogeneity between health and drinking history among non-drinkers.

Overall findings show that moderate drinkers have the best health in Ireland. While the health status of moderate and heavy drinkers is similar, slightly more moderate drinkers report very good/excellent health. Previous studies found a U-shaped curve depicting moderate drinkers having better health compared with abstainers or heavy drinkers (Bau et al., 2007; Berger et al., 1999; Klatsky et al., 2001), and this study is similar. However, the substantial drop in the health status of heavy drinkers is not evident. The difference between the health status of moderate drinkers and non-drinkers is greater than that of moderate drinkers and heavy drinkers.

In relation to health-care utilization, results show that more non-drinkers and those who never drank consulted a GP in the 4 weeks prior to the survey than either moderate drinkers or heavy drinkers. Both moderate and heavy drinkers utilized a GP approximately the same amount in the 4 weeks. In the year prior to the survey, non-drinkers and those who never drank utilized the GP services slightly more than both moderate and heavy drinkers.

The WHO (2007) states that there is a large body of evidence showing that not only do alcohol policies and interventions targeted at vulnerable populations prevent alcohol-related harm, but that policies targeted at the population at large can also have a protective effect on the population as a whole. Adams and White (2005) suggest that population-based approaches to policy aimed at reducing alcohol consumption may result in some individuals, namely moderate consumers of alcohol, being harmed or disadvantaged from such an approach. 
It is imperative that individuals who drink more than what is recommended are targeted in order to ensure that the consumption of alcohol is done in a safe manner that benefits all. However, given the findings of this study showing that moderate consumers of alcohol enjoy a better health status, it is recommended that both population-based policies and target-based policies be considered in relation to alcohol consumption in Ireland. 


\section{References}

Adams, J., \& White, M. (2005). When the population approach to prevention puts the health of individuals at risk. International Journal of Epidemiology, 34, 40-43.

Barrett, G. (2002). The Effect of Alcohol Consumption on Earnings. Economic Record, 78, 7996.

Bau, P. F., Bau, C. H., Rosito, G. A., Manfroi, W. C., \& Fuchs, F. D. (2007). Alcohol consumption, cardiovascular health, and endothelial function markers. Alcohol, 41, 479488.

Becker, U., Deis, A., Sørensen, T. I., Grønbaek, M., Borch-Johnsen, K., Müller, C. F., et al. (1996). Prediction of risk of liver disease by alcohol intake, sex, and age: a prospective population study. Hepatology, 23, 1025-1029.

Behrman, J. R., \& Wolfe, B. L. (1989). Does More Schooling Make Women Better Nourished and Healthier? Adult Sibling Random and Fixed Effects Estimates for Nicaragua. The Journal of Human Resources, 24, 644-663.

Berger, K., Ajani, U. A., Kase, C. S., Gaziano, J. M., Buring, J. E., Glynn, R. J., et al. (1999). Light-to-moderate alcohol consumption and risk of stroke among U.S. male physicians. The New England Journal of Medicine, 341, 1557-1564.

Berger, M. C., \& Leigh, J. P. (1989). Schooling, Self-Selection, and Health. The Journal of Human Resources, 24, 433-455.

Bryson, C. L., Mukamal, K. J., Mittleman, M. A., Fried, L. P., Hirsch, C. H., Kitzman, D. W., et al. (2006). The association of alcohol consumption and incident heart failure: the Cardiovascular Health Study. Journal of American College of Cardiology, 48, 305-311.

Buckley, N. J., Denton, F. T., Robb, A. L., \& Spencer, B. G. (2004). The transition from good to poor health: an econometric study of the older population. Journal of Health Economics, 23, 1013-1034.

Burton, S. M., \& Tiffany, S. T. (1997). The effect of alcohol consumption on craving to smoke. Addiction, 92, 15-26.

Chenhall, R., \& Moers, F. (2007). The Issue of Endogeneity within Theory-Based, Quantitative Management Accounting Research. European Accounting Review, 16, 173-196.

Chiburis, R., \& Lokshin, M. (2007). Maximum likelihood and two-step estimation of an orderedprobit selection model. The Stata Journal, 7, 167-182.

Contoyannis, P., \& Jones, A. M. (2004). Socio-economic status, health and lifestyle. Journal of Health Economics, 23, 965-995.

Department of Health, Ireland. (2014). Alcohol Literature Review. June 2014.

Di Pietro, G., \& Pedace, L. (2008). Changes in the returns to education in Argentina. Journal of Applied Economics, 11, 259-279.

Disney, R., Emmerson, C., \& Wakefield, M. (2006). Ill-health and retirement in Britain: a panel data-based analysis. Journal of Health Economics, 25, 621-649. 
Dunlop, S., Coyte, P. C., \& McIsaac, W. (2000). Socio-economic status and the utilisation of physicians' services: results from the Canadian National Population Health Survey. Social Science \& Medicine, 51, 123-133.

Fayers, P. M., \& Sprangers, M. A. (2002). Understanding self-related health. The Lancet, 359, $187-188$.

Fillmore, K. M., Golding, J. M., Leino, E. V., Ager, C. R., \& Ferrer, H. P. (1994). Societal-level predictors of groups' drinking patterns: a research synthesis from the Collaborative Alcohol-Related Longitudinal Project. American Journal of Public Health, 84, 247-253.

Finkelstein, M. M. (2001). Do factors other than need determine utilization of physicians' services in Ontario? Canadian Medical Association Journal, 165, 565-570.

Gerdtham, U., Johannesson, M., Lundberg, L., \& Isacson, D. (1999). The demand for health: results from new measures of health capital. European Journal of Political Economy, 15, 501-521.

Gilleskie, D., \& Harrison, A. (1998). The effect of endogenous health inputs on the relationship between health and education. Economics of Education Review, 17, 279-295.

Green, C. A., \& Polen, M. R. (2001). The health and health behaviors of people who do not drink alcohol. American Journal of Preventive Medicine, 21, 298-305.

Greene, W., \& Hensher, D. (2010). Modeling Ordered Choices: A Primer. Cambridge: Cambridge University Press.

Grossman, M. (1972). On the concept of health capital and the demand for health. Journal of Political Economy, 80, 223-255.

Gruber, S., \& Kiesel, M. (2010). Inequality in health care utilization in Germany? Theoretical and empirical evidence for specialist consultation. Journal of Public Health, 18, 351365.

Gulliver, S. B., Kamholz, B. W., \& Helstrom, A. W. (1995). Smoking cessation and alcohol abstinence: what to the data tell us? Alcohol Research \& Health, 29, 208-212.

Habicht, J., \& Kunst, A. E. (2005). Social inequalities in health care services utilisation after eight years of health care reforms: a cross sectional study of Estonia, 1999. Social Science and Medicine, 60, 777-787.

Hamilton, V., \& Hamilton, B. (1997). Alcohol and Earnings: Does Drinking Yield a Wage Premium? The Canadian Journal of Economics, 30, 135-151.

Harmon, C., \& Nolan, B. (2001). Health insurance and health services utilisation in Ireland. Health Economics, 10, 135-145.

Harris, M. N., Ramful, P., \& Shao, Z. (2006). An ordered generalised extreme value model with application to alcohol consumption in Australia. Journal of Health Economics, 25, 782801.

Hartog, J., \& Oosterbeek, H. (1998). Health, wealth and happiness: why pursue a higher education? Economics of Education Review, 17, 245-256. 
Health Service Executive (2008).

(URL:http://www.hse.ie/eng/services/news/Image_Bank/Alcohol_Awareness_Posters.pd f). (Accessed: 2008).

Heckman, J. (1979). Sample Selection Bias as a Specification Error. Econometrica, 47, 153-161.

Ho, S. Y., Lam, T. H., Fielding, R., \& Janus, E. D. (2003). Smoking and perceived health in Hong Kong Chinese. Social Science \& Medicine, 57, 1761-1770.

Höfter, R. (2006). Private health insurance and utilization of health services in Chile. Applied Economics, 38, 423-439.

Hurd, M. D., \& McGarry, K. (1997). Medical insurance and the use of health care services by the elderly. Journal of Health Economics, 16, 129-154.

Jürges, H. (2008). Self-assessed health, reference levels and mortality. Applied Economics, 40, 569-582.

Kenkel, D. S. (1991). Health Behavior, Health Knowledge, and Schooling. Journal of Political Economy, 99, 287-305.

Kenkel, D. S. (1995). Should you eat breakfast? Estimates from health production functions. Health Economics, 4, 15-29.

Kiuila, O., \& Mieszkowski, P. (2007). The effects of income, education and age on health. Health Economics, 16, 781-798.

Klatsky, A. L., Armstrong, M. A., Friedman, G. D., \& Sidney, S. (2001). Alcohol drinking and risk of hospitalization for ischemic stroke. The American Journal of Cardiology, 88, 703706.

Klatsky, A. L., Chartier, D., Udaltsova, N., Gronningen, S., Brar, S., Friedman, G. D., et al. (2005). Alcohol drinking and risk of hospitalization for heart failure with and without associated coronary artery disease. The American Journal of Cardiology, 96, 346-351.

Kwan, Y. K. (2010). Life Satisfaction and Self-Assessed Health Among Adolescents in Hong Kong. Journal of Happiness Studies, 11, 383-393.

Lahelma, E., Martikainen, P., Rahkonen, O., \& Silventoinen, K. (1999). Gender differences in illhealth in Finland: patterns, magnitude and change. Social Science \& Medicine, 48, $7-$ 19.

Laroche, M. (2000). Health Status and Health Services Utilization of Canada's Immigrant and Non-Immigrant Populations. Canadian Public Policy, 26, 51-75.

Leigh, J. (1998). Parents' schooling and the correlation between education and frailty. Economics of Education Review, 17, 349-358.

Lianga, J., Bennett, J. M., Sugisawac, H., Kobayashid, E., \& Fukayad, T. (2003). Gender differences in old age mortality: roles of health behavior and baseline health status. Journal of Clinical Epidemiology, 56, 572-582.

Lin, S. (2008). An analysis of lifestyles and health in Taiwan. Applied Economics Letters, 15, 399-404. 
Liu, L. (2008). Gender Difference of Health Status in Aging Population of Urban China. The Chinese Economy, 41, 58-71.

Madden, D., Nolan, A., \& Nolan, B. (2005). GP reimbursement and visiting behaviour in Ireland. Health Economics, 14, 1047-1060.

Manning, W., Keeler, E., Newhouse, J., Sloss, E., \& Wasserman, J. (1991). The Costs of Poor Health Habits. Cambridge: Harvard University Press.

Mathers, C. D., \& Loncar, D. (2006). Projections of global mortality and burden of disease from 2002 to 2030. PLoS Medicine, 3, e442.

Moore, A. A, Gould, R.; Reuben, D. B., Greendale, G. A., Carter, M. K., Zhou, K., et al. (2005). Longitudinal patterns and predictors of alcohol consumption in the United States. American Journal of Public Health, 95, 458-465.

Mukamal, K. (2007) Alcohol intake and noncoronary cardiovascular disease. Annals of Epidemiology, 17(5 Suppl), S8-S12.

Mullahy, J., \& Sindelar, J. (1996). Employment, unemployment, and problem drinking. Journal of Health Economics, 15, 409-434.

Ormond, G., \& Murphy, R. (2016). The effect of alcohol consumption on household income in Ireland. Alcohol, 56, 39-49.

Oslin, D. W., Slaymaker, V. J., Blow, F. C., Owen, P. L., \& Colleran, C. (2005). Treatment outcomes for alcohol dependence among middle-aged and older adults. Addictive Behaviors, 30, 1431-1436.

Ridolfo, B. \& Stevenson, C. (2001) The quantification of drug-caused mortality and morbidity in Australia 1988. Canberra: Australian Institute of Health and Welfare.

Rimm, E. M., \& Moats, C. (2007). Alcohol and Coronary Heart Disease: Drinking Patterns and Mediators of Effect. Annals of Epidemiology, 17, S3-S7.

Rivera, B. (2001). The effects of public health spending on self-assessed health status: an ordered probit model. Applied Economics, 33, 1313-1319.

Rosengren, A., Wedel, H., \& Wilhelmsen, L. (1989). Marital status and mortality in middle-aged Swedish men. American Journal of Epidemiology, 129, 54-64.

Rotermann, M. (2006). Seniors' Health Care Use. Statistics Canada Catalogue 82-003 Supplement to Health Reports, Volume 16.

Su, S., \& Yen, S. (2000). A censored system of cigarette and alcohol consumption. Applied Economics, 32, 729-737.

Thompson, O. (2011). Racial disparities in the cognition-health relationship. Journal of Health Economics, 30, 328-339.

Tremblay, S., Ross, N., \& Berthelot, J. (2002). Regional Socio-economic context and health. Supplement to Health Reports, 13: 1-12. Ottawa: Statistics Canada, Catalogue 82-002.

Vella, F. (1998). Estimating Models with Sample Selection Bias: A Survey. Journal of Human Resources, 33, 127-169. 
Wagstaff, A. (1986). The demand for health: a simplified Grossman model. Bulletin of Economic Research, 38, 93-95.

Wang, W. (1997). Semi-parametric estimation of the effect of health on labour force participation of married women. Applied Economics, 29, 325-329.

Wannamethee, S. G., \& Shaper, A. G. (1999). Type of alcoholic drink and risk of major coronary heart disease events and all-cause mortality. American Journal of Public Health, 89, 685690.

Williamson, D. F., Forman, M. R., Binkin, N. J., Gentry, E. M., Remington, P. L., \& Trowbridge, F. L. (1987). Alcohol and body weight in the United States adults. American Journal of Public Health, 77, 1324-1330.

Wilson, K., Rosenberg, M. W., \& Abonyi, S. (2011). Aboriginal peoples, health and healing approaches: the effects of age and place on health. Social Science \& Medicine, 72, 355364.

World Health Organization. (2007). WHO Expert Committee Report on Problems Related to Alcohol Consumption. Technical Report Series 944. Geneva, World Health Organization.

World Health Organization. (2009). Report on the Global Tobacco Epidemic, 2009: Implementing smoke free environments. World Health Organization.

World Health Organization. (2011). Global Status Report on Alcohol and Health. Geneva: World Health Organization.

World Health Organization. (2014). Global Status Report on Alcohol and Health. Geneva: World Health Organization.

Yen, S. T., Shaw, W. D., \& Yuan, Y. (2010). Cigarette smoking and self reported health in China. China Economic Review, 21, 532-543.

Zhang, H. (2004). Self Selection and Wage Differentials in Urban China: A Polychotomous Model with Selectivity. Cambridge, Massachusetts: Department of Urban Studies and Planning, Massachusetts Institute of Technology.

Zick, C., \& Smith, K. (1991). Marital Transitions, Poverty, and Gender Differences in Mortality. Journal of Marriage and Family, 53, 327-336. 


\section{Appendices}

Appendix A. Equations used in the estimation of the effect of alcohol consumption on health status

\section{Equation 1: Deriving the Inverse Mills Ratio}

$$
\begin{aligned}
& \hat{\lambda}_{i} \equiv \frac{\phi\left(\hat{\mu}_{J}-\hat{\alpha}^{\prime} s_{i}\right)-\phi\left(\hat{\mu}_{J+1}-\hat{\alpha}^{\prime} s_{i}\right)}{\Phi\left(\hat{\mu}_{J+1}-\hat{\alpha}^{\prime} s_{i}\right)-\Phi\left(\hat{\mu}_{J}-\hat{\alpha}^{\prime} s_{i}\right)} \quad \text { where } j=c_{i} \\
& =\frac{\phi\left(\hat{\mu}_{J}-\hat{c}_{i}\right)-\phi\left(\hat{\mu}_{J+1}-\hat{c}_{i}\right)}{\Phi\left(\hat{\mu}_{J+1}-\hat{c}_{i}\right)-\Phi\left(\hat{\mu}_{J}-\hat{c}_{i}\right)}
\end{aligned}
$$

Where: $\quad \alpha \quad$ is an unknown vector of parameters in the alcohol equation

$s \quad$ independent variables in the alcohol equation

$\mu_{J} \quad$ cut-offs

c category of drinker

$i \quad$ indexes individuals

$\phi \quad$ probability density function

$\Phi \quad$ cumulative distribution function

Equation 2: Estimation of the Primary Equation of Interest, Health Status, which included the inverse mills ratio.

$$
E\left(h_{i} \mid x_{i}, s_{i}, c_{i}=j\right)=\beta_{j} x_{i}+\rho_{j} \sigma_{j} \lambda_{j}^{\prime}
$$

Where: $\quad h \quad$ health measure of individual

$x \quad$ vector of independent variables

$s \quad$ independent variables in the selection equation

$c \quad$ category of drinker

$\beta \quad$ coefficients on the observable characteristics

$\rho_{j} \quad$ correlation of the error terms $\varepsilon_{i}$ and each of the $u_{i j}$ terms

$\sigma_{j} \quad$ standard deviation

$\lambda_{i} \quad$ ordered probit extension of the Inverse Mills Ratio

$\phi \quad$ probability density function

$\Phi \quad$ cumulative distribution function

$i \quad$ indexes individuals 


\section{Appendix B}

Table B1. Results of the ordered probit regression of alcohol status in Step 1 of the estimation of the effect of alcohol consumption on health status

Table B1. Ordered probit model estimating drinking status results

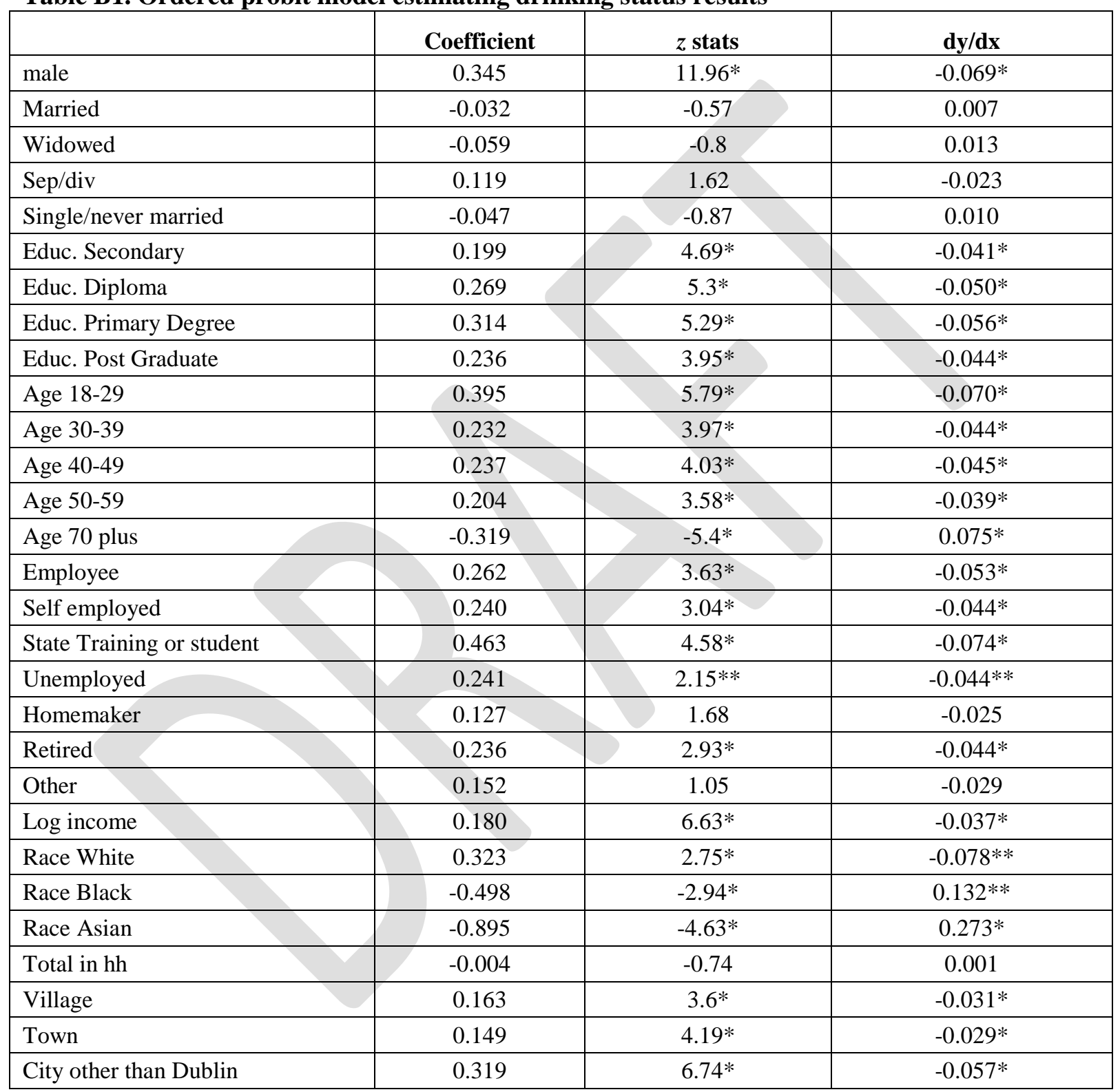


Table B1 continued. Ordered probit model estimating drinking status results

\begin{tabular}{|l|c|c|c|}
\hline & Coefficient & z stats & $\mathbf{d y} / \mathbf{d x}$ \\
\hline Dublin city & 0.248 & $6.68^{*}$ & $-0.047^{*}$ \\
\hline Smoker & 0.349 & $11.29^{*}$ & $-0.066^{*}$ \\
\hline Weight right & 0.184 & $3.19^{*}$ & $-0.038^{*}$ \\
\hline Weight too heavy & 0.265 & $4.45^{*}$ & $-0.052^{*}$ \\
\hline Weight too light & 0.174 & 1.96 & $-0.033^{* *}$ \\
\hline Medical Card Holder & 0.027 & 0.68 & -0.006 \\
\hline Health Insurance & 0.077 & $2.47^{* *}$ & -0.016 \\
\hline Church activities & -0.147 & $-4.47^{*}$ & $0.032^{*}$ \\
\hline Cut Off 1 & 1.444 & & \\
\hline Cut Off 2 & 1.942 & & \\
\hline Cut Off 3 & 4.271 & & \\
\hline
\end{tabular}

No. of Observations $=8519$

Wald chi2 $(37)=1358.82$

Prob $>$ chi $2=0.0000$

Pseudo $\mathrm{R}^{2}=.0853$

Log Pseudolikelihood $=-7798.4575$

Marginal effects after oprobit $\mathrm{y}=\operatorname{Pr}($ alcohol status $=1)=.12559$

(*) dy/dx is for discrete change of dummy variable from 0 to 1

\section{* indicates significance at $1 \%$ and $5 \%$ level}

Note: The average price of alcohol was included as a variable in the alcohol-status equation. The price was derived by dividing the total values of sales in the year 2006 by the total volume sold for each type of alcohol in 2006. Price was dropped due to colinearity and the variable Physically Active was also dropped due to colinearity.

The first independent variable considered is gender, whereby the results show that this is a statistically significant variable in the alcohol-status equation. Males are more likely to be in a higher drinking category than females, which is similar to the findings in previous studies (Oslin et al., 2005; Fillmore, Golding, Leino, Ager, \& Ferrer, 1994; Moore et al., 2005; Mullahy \& Sindelar, 1996). Females are less likely to be in a higher drinking category than males and are more likely to be non-drinkers or moderate drinkers. Marginal effects show that males are $6.9 \%$ less likely to never having drank.

None of the variables describing marital status is significant in terms of alcohol status.

The explanatory variables describing individuals' levels of education are all significant and all are positively correlated with alcohol status. Those with a primary degree are more likely to be 
heavy drinkers which is different from the findings of Hamilton and Hamilton (1997), who found that higher-educated people, those with third-level degrees, tend to consume moderate amounts of alcohol and they are less likely to abstain or be heavy drinkers.

The variable 'Age' is also significant in terms of alcohol consumption. All ages up to 59 years are positively correlated with alcohol status. In particular, those aged 18-29 years are more likely to be in a higher drinking category and are $7 \%$ less likely to be lifetime abstainers. Similar to the findings of Hamilton and Hamilton (1997) and Barrett (2002), those aged 70 years or over are less likely to be in a higher drinking category and are $7.5 \%$ more likely to never having drank.

All the variables describing Employment Status are significant except those in the 'Other' category. In particular, those on state training schemes (government-subsidized training programs) or students are more likely to be in a higher category of drinking, with marginal effects showing that they are $7.4 \%$ less likely to be lifetime abstainers. Homemakers are the least likely to be in a higher drinking category.

Log of income is statistically significant. As income increases, the respondents are more likely to be in a higher drinking category, hence showing a positive correlation between income and drinking.

The explanatory variables describing race are all significant. A white person, either white Irish or a person of any other white background, is more likely to be in a higher drinking category compared with those of other races. They are $7.8 \%$ less likely to be a non-drinker. Both Blacks and Asians are less likely to be in a higher drinking category. Blacks are $13.2 \%$ more likely to never have been drinkers, and Asians are $27.3 \%$ more likely to never have drank. Similarly, Mullahy and Sindelar (1996) and Moore et al. (2005) found that white people tend to consume greater amounts of alcohol and that those who abstain from alcohol tend less often to be white.

Total number of people in the household is not significant in the determination of alcohol consumption.

Where a person lives is a significant variable in terms of alcohol consumption. Those who live in Dublin are $4.7 \%$ less likely to be lifetime abstainers of alcohol and those living in a city other than Dublin are $5.7 \%$ less likely to be lifetime abstainers and more likely to be in a higher drinker category, which is similar to the findings of Su and Yen (2000). 
In terms of the lifestyle variables, smoking is highly significant and is positively correlated with alcohol consumption. A smoker is $6.6 \%$ less likely to never have drank compared with a nonsmoker, which is similar to previous findings (Burton \& Tiffany, 1997; Gulliver, Kamholz, \& Helstrom, 1995).

The variable 'Physically Active' is dropped due to colinearity. The variables describing selfassessed weight as being right or too heavy are significant. In particular, those who described their weight as too heavy are more likely to consume higher amounts of alcohol. Previous studies show that alcohol has only a slight effect on weight (Williamson et al., 1987).

Having health insurance is significant. Those with health insurance are $1.6 \%$ less likely to be a lifetime abstainer. Having a medical card is not significant.

The additional explanatory variable that is included in the alcohol-status equation but not in the health-status equation is whether respondents regularly partake in church activities. This is a highly significant variable with a $p$ value of 0 . Church activities are negatively correlated with alcohol consumption. Those who regularly partake in church activities are less likely to be in a higher drinking category, compared with those who do not regularly partake in church activities, and are in fact $3.2 \%$ more likely to be a non-drinker, which is similar to what Hamilton and Hamilton (1997) found in their study. 
Table B2. Marginal effects of ordered probit regression of health status by drinker type

\begin{tabular}{|c|c|c|c|c|c|c|c|c|}
\hline & \multicolumn{2}{|c|}{ Never Drank } & \multicolumn{2}{|c|}{ Non Drinkers } & \multicolumn{2}{|c|}{ Moderate Drinkers } & \multicolumn{2}{|c|}{ Heavy Drinkers } \\
\hline Variable & $\mathrm{dy} / \mathrm{dx}$ & $z$ stat & $\mathrm{dy} / \mathrm{dx}$ & $z$ stat & $d y / d x$ & $z$ stat & $d y / d x$ & $z$ stat \\
\hline edseco $\sim y^{*}$ & -0.027 & $-3.87 *$ & -0.010 & -1.54 & -0.005 & $-3.58^{*}$ & -0.006 & -0.97 \\
\hline eddipl $t^{*}$ & -0.019 & $-3.39 *$ & -0.023 & $-3.68 *$ & -0.004 & $-3.81 *$ & -0.004 & -0.85 \\
\hline edprim $\mathrm{e}^{*}$ & -0.021 & $-3.91 *$ & -0.025 & $-4.36^{*}$ & -0.005 & $-5.13^{*}$ & -0.004 & -0.88 \\
\hline edpost $\sim \mathrm{e}^{*}$ & -0.017 & $-2.87 *$ & -0.017 & $-2.53 *$ & -0.006 & $-5.78^{*}$ & -0.003 & -0.58 \\
\hline age18 29* & -0.036 & $-6.92 *$ & -0.034 & $-5.5 *$ & -0.007 & $-5.46^{*}$ & -0.010 & -1.4 \\
\hline age30 39* & -0.031 & $-6.3^{*}$ & -0.032 & $-4.42 *$ & -0.006 & $-4.73 *$ & -0.010 & -1.95 \\
\hline age $40 \sim 49 *$ & -0.026 & $-4.93 *$ & -0.027 & $-4.2 *$ & -0.005 & $-3.83 *$ & -0.010 & -1.96 \\
\hline age $50 \sim 59 *$ & -0.024 & $-4.74 *$ & -0.004 & -0.45 & 0.000 & -0.07 & -0.006 & -1.41 \\
\hline age70p s* & 0.044 & $2.73 *$ & 0.021 & 1.49 & -0.002 & -0.92 & 0.005 & 0.33 \\
\hline employee* & -0.064 & $-6.28 *$ & -0.070 & $-5.44 *$ & -0.032 & $-6.53 *$ & -0.040 & -1.91 \\
\hline selfem $\sim r^{*}$ & -0.033 & $-6.79 *$ & -0.040 & $-6.57 *$ & -0.011 & $-8.15^{*}$ & -0.010 & $-2.39 * *$ \\
\hline statet $\sim \mathrm{d}^{*}$ & -0.029 & $-6.99 *$ & -0.031 & $-6.1 *$ & -0.009 & $-7.97 *$ & -0.008 & $-2.36 * *$ \\
\hline unempl $\sim \mathrm{d}^{*}$ & -0.028 & $-7.04 *$ & -0.030 & $-5.87 *$ & -0.009 & $-7.95^{*}$ & -0.008 & $-2.38 * *$ \\
\hline homema $\sim$ r $^{*}$ & -0.042 & $-6.34 *$ & -0.040 & $-5.91 *$ & -0.011 & $-7.98 *$ & -0.007 & $-2.34 * *$ \\
\hline retired* & -0.061 & $-5.48 *$ & -0.039 & $-5.15^{*}$ & -0.010 & $-7.55 *$ & -0.009 & $-2.37 * *$ \\
\hline other* & -0.025 & $-6.21 *$ & -0.030 & $-5.85^{*}$ & -0.008 & $-7.83^{*}$ & 0.036 & 0.65 \\
\hline $\operatorname{loginc} \sim \mathrm{e}$ & -0.020 & $-3.13^{*}$ & -0.005 & -0.9 & -0.003 & $-3.5^{*}$ & -0.005 & -1.11 \\
\hline racewh $\mathrm{e}^{*}$ & -0.020 & -0.9 & -0.013 & -0.48 & 0.002 & 0.67 & -0.021 & -0.65 \\
\hline raceblack & 0.064 & 1.11 & -0.023 & -1.97 & 0.006 & 0.71 & & \\
\hline raceas $\sim n^{*}$ & 0.398 & $2.27 * *$ & 0.012 & 0.27 & 0.003 & 0.36 & 0.011 & 0.26 \\
\hline male* & -0.024 & $-2.78 *$ & 0.001 & 0.19 & 0.003 & $3.4^{*}$ & -0.001 & -0.15 \\
\hline married* & 0.009 & 0.85 & -0.026 & $-2.13 * *$ & -0.003 & -1.86 & 0.001 & 0.15 \\
\hline widowed* & 0.002 & 0.15 & -0.028 & $-4.03 *$ & -0.001 & -0.41 & 0.000 & -0.07 \\
\hline sepdiv* & -0.001 & -0.09 & -0.020 & $-2.54 * *$ & -0.002 & -1.55 & 0.002 & 0.28 \\
\hline single $\sim d^{*}$ & 0.006 & 0.5 & -0.015 & -1.54 & -0.002 & -1.79 & 0.002 & 0.58 \\
\hline
\end{tabular}


Table B2 continued. Marginal effects of ordered probit regression of health status by drinker type

\begin{tabular}{|c|c|c|c|c|c|c|c|c|}
\hline & \multicolumn{2}{|c|}{ Never Drank } & \multicolumn{2}{|c|}{ Non Drinkers } & \multicolumn{2}{|c|}{ Moderate Drinkers } & \multicolumn{2}{|c|}{ Heavy Drinkers } \\
\hline Variable & $d y / d x$ & $z$ stat & $\mathrm{dy} / \mathrm{dx}$ & $z$ stat & $d y / d x$ & $z$ stat & $d y / d x$ & $z$ stat \\
\hline totali $\sim \mathrm{h}$ & 0.001 & 1.03 & -0.001 & -1.19 & 0.000 & 1.54 & 0.000 & -0.78 \\
\hline village* & -0.004 & -0.6 & 0.003 & 0.38 & 0.001 & 0.78 & 0.000 & 0.08 \\
\hline town* & 0.004 & 0.6 & -0.007 & -1.21 & 0.002 & $2.15 * *$ & 0.000 & -0.1 \\
\hline cityot $\sim n^{*}$ & -0.019 & $-3.31 *$ & -0.008 & -0.98 & -0.001 & -1.1 & -0.003 & -0.68 \\
\hline dublin $\sim y^{*}$ & -0.014 & $-2.14 * *$ & -0.005 & -0.69 & 0.000 & -0.17 & -0.001 & -0.28 \\
\hline smoker* & -0.011 & -1.38 & 0.010 & 1.09 & 0.007 & $5.22 *$ & 0.001 & 0.11 \\
\hline we right $*$ & -0.029 & $-2.68 *$ & 0.000 & -0.02 & 0.001 & 0.57 & -0.002 & -0.42 \\
\hline weight $\sim y^{*}$ & -0.013 & -1.55 & 0.031 & $2.04 * *$ & 0.009 & $3.68 *$ & 0.003 & 0.4 \\
\hline we light* & -0.002 & -0.13 & 0.108 & $2.18 * *$ & 0.009 & $2.03 * *$ & 0.007 & 0.56 \\
\hline medcar $\sim \mathrm{r}^{*}$ & 0.008 & 1.49 & 0.015 & $2.26 * *$ & 0.005 & $4.13 *$ & -0.003 & -1.27 \\
\hline health $\sim \mathrm{e}^{*}$ & -0.020 & $-4.02 *$ & -0.005 & -0.8 & -0.002 & $-2.34 * *$ & -0.003 & -0.95 \\
\hline Mills Ratio & 0.108 & $2.91 *$ & 0.035 & 0.97 & 0.009 & 1.61 & -0.016 & -0.67 \\
\hline
\end{tabular}

Never Drank $\quad \mathrm{y}=\operatorname{Pr}($ healthstatusoprobit $==1)($ predict $)=0.02640702$

Non-Drinkers $\quad y=\operatorname{Pr}($ healthstatusoprobit=-1) (predict $)=.0315208$

Moderate Drinkers $\quad \mathrm{y}=\operatorname{Pr}($ healthstatusoprobit==1) (predict) $=0.00790495$

Heavy Drinkers $\quad \mathrm{y}=\operatorname{Pr}($ healthstatusoprobit==1) (predict) $=0.00661192$

(*) dy/dx is for discrete change of dummy variable from 0 to 1

* indicates significance at $1 \%$ and $5 \%$ level 


\section{Appendix C. Results in the estimation of health care utilization}

In the estimation of the effect of alcohol on health-care utilization, both alcohol and health status are estimated as an ordered probit. The results of the ordered probit estimates of the alcoholstatus equation estimated in Step 1 along with the marginal effects are set out below. The results of the health-care utilization estimation and the marginal effects estimated in Step 2 are also set out below.

Table C1. Results of the ordered probit regression of alcohol status in the estimation of the effect of alcohol consumption on health care utilization

\begin{tabular}{|l|c|c|c|}
\hline Variable & Coefficient & z-stat & dy/dx \\
\hline healthexce $\sim \mathrm{t}$ & 0.335 & $4.05^{*}$ & $-0.06^{*}$ \\
\hline healthvery d & 0.329 & $4.14^{*}$ & $-0.06^{*}$ \\
\hline healthgood & 0.336 & $4.27^{*}$ & $-0.06^{*}$ \\
\hline healthfair & 0.223 & $2.73^{*}$ & $-0.04^{*}$ \\
\hline edsecondary & 0.183 & $4.24^{*}$ & $-0.04^{*}$ \\
\hline eddiplomac $\sim \mathrm{t}$ & 0.257 & $5.03^{*}$ & $-0.05^{*}$ \\
\hline edprimaryd e & 0.301 & $5.03^{*}$ & $-0.05^{*}$ \\
\hline edpostgrad e & 0.222 & $3.68^{*}$ & $-0.04^{*}$ \\
\hline age18to29 & 0.389 & $5.64^{*}$ & $-0.07^{*}$ \\
\hline age30to39 & 0.224 & $3.82^{*}$ & $-0.04^{*}$ \\
\hline age40to49 & 0.234 & $3.97^{*}$ & $-0.04^{*}$ \\
\hline age50to59 & 0.217 & $3.79^{*}$ & $-0.04^{*}$ \\
\hline age70plus & -0.307 & $-5.15^{*}$ & $0.07^{*}$ \\
\hline employee & 0.164 & $2.16^{* *}$ & $-0.03^{* *}$ \\
\hline selfemplin r & 0.142 & 1.72 & -0.03 \\
\hline statetrain d & 0.359 & $3.42^{*}$ & $-0.06^{*}$ \\
\hline unemployed & 0.141 & 1.22 & -0.03 \\
\hline homemaker & 0.039 & 0.5 & -0.01 \\
\hline retired & 0.156 & 1.87 & $-0.03^{* *}$ \\
\hline other & 0.056 & 0.38 & -0.01 \\
\hline logincome & 0.173 & $6.37^{*}$ & $-0.04^{*}$ \\
\hline racewhite & 0.339 & $2.86^{*}$ & $-0.08^{* *}$ \\
\hline raceblack & -0.494 & $-2.89^{* *}$ & $0.13^{* *}$ \\
\hline raceasian & -0.912 & $-4.66^{* *}$ & $0.28^{*}$ \\
\hline male & 0.352 & $12.09^{*}$ & $-0.07^{*}$ \\
\hline
\end{tabular}


Table $\mathrm{C} 1$ continued. Results of the ordered probit regression of alcohol status in the estimation of the effect of alcohol consumption on health care utilization

\begin{tabular}{|l|c|c|c|}
\hline Variable & Coefficient & $\boldsymbol{z}$ stat & $\mathbf{d y} / \mathbf{d x}$ \\
\hline married & -0.027 & -0.49 & 0.01 \\
\hline widowed & -0.060 & -0.79 & 0.01 \\
\hline sepdiv & 0.117 & 1.59 & -0.02 \\
\hline singleneve d & -0.043 & -0.78 & 0.01 \\
\hline totalinhh & -0.004 & -0.75 & 0.00 \\
\hline village & 0.164 & $3.63^{*}$ & $-0.03^{*}$ \\
\hline town & 0.152 & $4.27^{*}$ & $-0.03^{*}$ \\
\hline cityothert n & 0.317 & $6.68^{*}$ & $-0.06^{*}$ \\
\hline dublincity $\sim \mathrm{y}$ & 0.250 & $6.69^{*}$ & $-0.05^{*}$ \\
\hline smoker & 0.354 & $11.36^{*}$ & $-0.07^{*}$ \\
\hline weightright & 0.162 & $2.8^{*}$ & $-0.03^{*}$ \\
\hline weighttooh y & 0.251 & $4.19^{*}$ & $-0.05^{*}$ \\
\hline weighttool t & 0.176 & $1.96^{*}$ & $-0.03^{* *}$ \\
\hline medcardhol r & 0.036 & 0.89 & -0.01 \\
\hline healthinsu $\sim \mathrm{e}$ & 0.071 & $2.29^{* *}$ & $-0.01^{* *}$ \\
\hline churchact & -0.155 & $-4.67^{*}$ & $0.03^{*}$ \\
\hline /cut1 & 1.615 & & \\
\hline /cut2 & 2.113 & & \\
\hline /cut3 & 4.448 & & \\
\hline
\end{tabular}

Number of obs $=8455 \quad$ LR Chi2 $(41)=1375.45 \quad$ Prob $>$ Chi $2=0$

Log Pseudolikelihood $=0.0863 \quad$ Pseudo $\mathrm{R}^{2}=.0863$

Marginal effects after oprobit $\mathrm{y}=\operatorname{Pr}($ alcohol status $==1)=.124601$

$\left.{ }^{*}\right)$ dy/dx is for discrete change of dummy variable from 0 to 1

* indicates significance at $1 \%$ and $5 \%$ level

Note: variable 'Physically Active' dropped due to colinearity 
Table C2. Ordered probit regression of health-care utilization by drinker type

\begin{tabular}{|c|c|c|c|c|c|c|c|c|}
\hline \multirow[b]{2}{*}{ Variable } & \multicolumn{2}{|c|}{ Never Drank } & \multicolumn{2}{|c|}{ Non Drinkers } & \multicolumn{2}{|c|}{ Moderate Drinkers } & \multicolumn{2}{|c|}{ Heavy Drinkers } \\
\hline & Coefficient & z stat & Coefficient & z stat & Coefficient & z stat & Coefficient & z stat \\
\hline healthexce t & -1.226 & $-5.25^{*}$ & -0.907 & $-4.82^{*}$ & -1.206 & $-7.93^{*}$ & -1.690 & $-2.89 *$ \\
\hline healthvery d & -1.058 & $-4.7^{*}$ & -0.840 & $-4.85^{*}$ & -1.044 & $-6.96 *$ & -1.492 & $-2.63^{*}$ \\
\hline healthgood & -0.844 & $-3.85^{*}$ & -0.685 & $-4.06^{*}$ & -0.837 & $-5.61 *$ & -1.272 & $-2.21 * *$ \\
\hline healthfair & -0.494 & $-2.41 * *$ & -0.105 & -0.6 & -0.382 & $-2.49 * *$ & -1.077 & $-2.16^{* *}$ \\
\hline edsecondary & 0.137 & 1.26 & 0.028 & 0.27 & 0.017 & 0.29 & 0.087 & 0.32 \\
\hline eddiplomac $\sim \mathrm{t}$ & 0.310 & $1.99 * *$ & 0.049 & 0.36 & 0.048 & 0.72 & -0.105 & -0.3 \\
\hline edprimaryd $\sim$ e & 0.403 & $2.08^{* *}$ & 0.123 & 0.72 & 0.000 & -0.01 & 0.042 & 0.1 \\
\hline edpostgrad e & 0.034 & 0.19 & 0.109 & 0.58 & 0.060 & 0.8 & 0.265 & 0.79 \\
\hline age18to29 & -0.041 & -0.16 & 0.667 & $3.23 *$ & -0.178 & -2.07 & -0.269 & -0.5 \\
\hline age30to39 & -0.259 & -1.39 & 0.314 & $2.01^{* *}$ & -0.184 & $-2.52 * *$ & -0.161 & -0.44 \\
\hline age40to49 & -0.287 & -1.65 & 0.023 & 0.15 & -0.251 & $-3.45^{*}$ & -0.176 & -0.46 \\
\hline age50to59 & -0.292 & -1.81 & 0.085 & 0.6 & -0.136 & -1.91 & 0.042 & 0.12 \\
\hline age70plus & -0.209 & -1.3 & 0.098 & 0.7 & 0.143 & 1.6 & 0.601 & 1.18 \\
\hline employee & -0.218 & -0.98 & -0.689 & $-3.85^{*}$ & -0.514 & $-4.84 *$ & 0.146 & 0.47 \\
\hline selfemplin $\sim r$ & -0.545 & $-2.31 * *$ & -0.835 & $-4.17^{*}$ & -0.492 & $-4.4^{*}$ & 0.220 & 0.71 \\
\hline statetrain d & -0.911 & $-2.84^{*}$ & -0.777 & $-2.78^{*}$ & -0.479 & $-3.62^{*}$ & 0.214 & 0.43 \\
\hline unemployed & -0.350 & -1.27 & -0.879 & $-3.37^{*}$ & -0.353 & $-2.47^{* *}$ & -0.132 & -0.4 \\
\hline homemaker & -0.423 & -2.02 & -0.793 & $-4.31^{*}$ & -0.424 & $-3.75^{*}$ & 0.579 & 1.77 \\
\hline retired & -0.279 & -1.32 & -0.514 & $-2.69 *$ & -0.343 & $-2.81^{*}$ & 0.340 & 0.87 \\
\hline other & -0.391 & -1.13 & -0.743 & -1.75 & -0.573 & $-3.07^{*}$ & -0.222 & -0.21 \\
\hline logincome & 0.199 & 1.9 & 0.018 & 0.22 & 0.011 & 0.35 & -0.025 & -0.11 \\
\hline racewhite & 0.306 & 1.26 & -0.284 & -1.03 & 0.080 & 0.58 & -0.001 & 0 \\
\hline raceblack & 0.054 & 0.14 & -0.405 & -1.01 & 0.155 & 0.66 & & \\
\hline raceasian & -0.112 & -0.24 & -0.838 & $-2.18 * *$ & -0.613 & -1.93 & -1.720 & -1.49 \\
\hline
\end{tabular}


Table C2 continued. Ordered probit regression of health-care utilization by drinker type

\begin{tabular}{|c|c|c|c|c|c|c|c|c|}
\hline & \multicolumn{2}{|c|}{ Never Drank } & \multicolumn{2}{|c|}{ Non Drinkers } & \multicolumn{2}{|c|}{ Moderate Drinkers } & \multicolumn{2}{|c|}{ Heavy Drinkers } \\
\hline Variable & Coefficient & $z$ stat & Coefficient & z stat & Coefficient & z stat & Coefficient & $z$ stat \\
\hline male & -0.106 & -0.6 & -0.323 & $-2.88^{*}$ & -0.359 & $-9.35^{*}$ & -0.339 & -0.83 \\
\hline married & 0.098 & 0.43 & 0.540 & $3.15^{*}$ & 0.034 & 0.56 & 0.012 & 0.06 \\
\hline widowed & -0.030 & -0.12 & 0.614 & $2.95 *$ & -0.053 & -0.55 & 0.207 & 0.59 \\
\hline sepdiv & 0.035 & 0.13 & 0.340 & 1.66 & -0.044 & -0.53 & 0.065 & 0.24 \\
\hline singleneve $\sim d$ & -0.144 & -0.62 & 0.175 & 1.05 & -0.049 & -0.8 & -0.084 & -0.47 \\
\hline totalinhh & -0.014 & -1.01 & -0.036 & $-2.69 *$ & -0.009 & -1.43 & 0.001 & 0.04 \\
\hline village & 0.078 & 0.59 & -0.090 & -0.72 & -0.080 & -1.43 & -0.257 & -1.03 \\
\hline town & 0.003 & 0.03 & 0.160 & 1.58 & -0.083 & -1.93 & -0.063 & -0.27 \\
\hline cityothert $\sim n$ & 0.154 & 0.83 & -0.051 & -0.38 & -0.023 & -0.39 & 0.019 & 0.05 \\
\hline dublincity $\sim y$ & 0.091 & 0.63 & -0.008 & -0.07 & -0.027 & -0.61 & 0.045 & 0.14 \\
\hline smoker & 0.098 & 0.55 & 0.011 & 0.09 & -0.020 & -0.51 & -0.048 & -0.12 \\
\hline weightright & -0.072 & -0.5 & 0.244 & 1.58 & -0.016 & -0.21 & -0.419 & -1.03 \\
\hline weighttooh y & -0.050 & -0.3 & 0.297 & 1.81 & 0.054 & 0.68 & -0.191 & -0.41 \\
\hline weighttool t & 0.226 & 1.04 & -0.137 & -0.56 & -0.167 & -1.52 & 0.053 & 0.12 \\
\hline medcardhol $\sim r$ & 0.631 & $6.6^{*}$ & 0.318 & $3.14 *$ & 0.331 & $7.12^{*}$ & 0.675 & $4.59 *$ \\
\hline healthinsu ${ }^{\sim}$ e & 0.148 & 1.85 & 0.095 & 1.06 & 0.142 & $3.86 *$ & 0.334 & $2.37^{* *}$ \\
\hline mills_alco 1 & -0.332 & -0.58 & -0.210 & -0.4 & -0.098 & -0.39 & -0.122 & -0.09 \\
\hline /cut1 & -2.301 & & -3.707 & & -3.991 & & -4.663 & \\
\hline /cut2 & -1.326 & & -2.584 & & -2.826 & & -3.066 & \\
\hline /cut3 & -0.928 & $\bar{F}$ & -2.097 & & -2.273 & & -2.494 & \\
\hline /cut4 & 0.564 & & -0.749 & & -0.761 & & -1.042 & \\
\hline
\end{tabular}


Table C3. Marginal effects of ordered probit regression of health-care utilization by drinker type

\begin{tabular}{|c|c|c|c|c|c|c|c|c|}
\hline & \multicolumn{2}{|c|}{ Never Drank } & \multicolumn{2}{|c|}{ Non-Drinkers } & \multicolumn{2}{|c|}{ Moderate Drinkers } & \multicolumn{2}{|c|}{ Heavy Drinkers } \\
\hline Variable & $d y / d x$ & $z$ stat & $d y / d x$ & $z$ stat & $d y / d x$ & $z$ stat & $d y / d x$ & $z$ stat \\
\hline healthexce t & 0.075 & $2.45 * *$ & 0.024 & $2.05 * *$ & 0.055 & $3.77 *$ & 0.071 & 1.06 \\
\hline healthvery d & 0.042 & $2.48 * *$ & 0.016 & $2.28 * *$ & 0.030 & $3.95 *$ & 0.034 & 1.07 \\
\hline healthgood & 0.029 & $2.23 * *$ & 0.012 & $2.08 * *$ & 0.026 & $3.25 *$ & 0.027 & 0.96 \\
\hline healthfair & 0.016 & 1.59 & 0.001 & 0.54 & 0.010 & 1.72 & 0.033 & 0.86 \\
\hline edsecondary & -0.003 & -1.24 & 0.000 & -0.27 & 0.000 & -0.29 & -0.001 & -0.32 \\
\hline eddiplomac $\sim \mathrm{t}$ & -0.005 & -2.23 & 0.000 & -0.38 & -0.001 & -0.74 & 0.001 & 0.27 \\
\hline edprimaryd e & -0.006 & $-2.59 * *$ & -0.001 & -0.79 & 0.000 & 0.01 & 0.000 & -0.11 \\
\hline edpostgrad e & -0.001 & -0.2 & -0.001 & -0.66 & -0.001 & -0.84 & -0.002 & -0.97 \\
\hline age18to29 & 0.001 & 0.15 & -0.004 & $-2.67 *$ & 0.004 & 1.74 & 0.003 & 0.4 \\
\hline age30to39 & 0.007 & 1.09 & -0.003 & -1.92 & 0.004 & $2.16^{* *}$ & 0.002 & 0.37 \\
\hline age40to49 & 0.008 & 1.27 & 0.000 & -0.16 & 0.005 & $2.75^{*}$ & 0.002 & 0.39 \\
\hline age50to59 & 0.008 & 1.36 & -0.001 & -0.64 & 0.003 & 1.67 & 0.000 & -0.13 \\
\hline age70plus & 0.005 & 1.11 & -0.001 & -0.74 & -0.002 & -1.82 & -0.003 & -1.41 \\
\hline employee & 0.005 & 0.84 & 0.010 & $2.06 * *$ & 0.009 & $3.93 *$ & -0.001 & -0.46 \\
\hline selfemplin $\sim \mathrm{r}$ & 0.020 & 1.42 & 0.023 & 1.95 & 0.014 & $2.79 *$ & -0.001 & -0.83 \\
\hline statetrain $\sim \mathrm{d}$ & 0.054 & 1.43 & 0.023 & 1.3 & 0.015 & $2.23 * *$ & -0.001 & -0.55 \\
\hline unemployed & 0.011 & 0.88 & 0.030 & 1.47 & 0.010 & 1.69 & 0.001 & 0.32 \\
\hline homemaker & 0.012 & 1.44 & 0.018 & 2 & 0.011 & $2.52 * *$ & -0.002 & -1.58 \\
\hline retired & 0.007 & 1.11 & 0.009 & 1.59 & 0.008 & $2.04 * *$ & -0.002 & -1.07 \\
\hline other & 0.013 & 0.76 & 0.022 & 0.85 & 0.021 & 1.78 & 0.003 & 0.16 \\
\hline logincome & -0.004 & -1.69 & 0.000 & -0.22 & 0.000 & -0.35 & 0.000 & 0.11 \\
\hline racewhite & -0.009 & -0.91 & 0.002 & 1.33 & -0.002 & -0.53 & 0.000 & 0 \\
\hline raceblack & -0.001 & -0.15 & 0.007 & 0.62 & -0.002 & -0.81 & 0.140 & 0.55 \\
\hline raceasian & 0.003 & 0.21 & 0.028 & 1.02 & 0.023 & 1.09 & 0.002 & 0.8 \\
\hline
\end{tabular}


Table C3 continued. Marginal effects of ordered probit regression of health-care utilization by drinker type

\begin{tabular}{|c|c|c|c|c|c|c|c|c|}
\hline & \multicolumn{2}{|c|}{ Never Drank } & \multicolumn{2}{|c|}{ Non Drinkers } & \multicolumn{2}{|c|}{ Moderate Drinkers } & \multicolumn{2}{|c|}{ Heavy Drinkers } \\
\hline & $d y / d x$ & z-stat & $d y / d x$ & z-stat & $d y / d x$ & z-stat & $d y / d x$ & z-stat \\
\hline male & 0.002 & 0.57 & 0.004 & 1.88 & 0.007 & $6.08 *$ & 0.000 & -0.06 \\
\hline married & -0.002 & -0.42 & -0.006 & $-2.22 * *$ & -0.001 & -0.56 & -0.001 & -0.73 \\
\hline widowed & 0.001 & 0.12 & -0.004 & $-2.63 *$ & 0.001 & 0.52 & 0.000 & -0.26 \\
\hline sepdiv & -0.001 & -0.13 & -0.002 & -1.95 & 0.001 & 0.5 & 0.001 & 0.45 \\
\hline singleneve $\sim \mathrm{d}$ & 0.003 & 0.56 & -0.002 & -1.13 & 0.001 & 0.77 & 0.000 & -0.04 \\
\hline totalinhh & 0.000 & 0.97 & 0.000 & $2.07 * *$ & 0.000 & 1.41 & 0.003 & 0.69 \\
\hline village & -0.001 & -0.62 & 0.001 & 0.65 & 0.002 & 1.31 & 0.001 & 0.25 \\
\hline town & 0.000 & -0.03 & -0.002 & -1.5 & 0.002 & 1.79 & 0.000 & -0.05 \\
\hline cityothert $\sim \mathrm{n}$ & -0.003 & -0.96 & 0.001 & 0.36 & 0.000 & 0.39 & 0.000 & -0.14 \\
\hline dublincity $\sim y$ & -0.002 & -0.66 & 0.000 & 0.07 & 0.000 & 0.6 & 0.000 & 0.12 \\
\hline smoker & -0.002 & -0.58 & 0.000 & -0.09 & 0.000 & 0.5 & 0.071 & 1.06 \\
\hline Weightright & 0.001 & 0.5 & -0.003 & -1.35 & 0.000 & 0.21 & 0.004 & 0.92 \\
\hline weighttooh $\sim y$ & 0.001 & 0.29 & -0.003 & -1.67 & -0.001 & -0.69 & 0.002 & 0.38 \\
\hline weighttool t & -0.004 & -1.31 & 0.002 & 0.48 & 0.004 & 1.25 & 0.000 & -0.12 \\
\hline medcardhol $\sim \mathrm{r}$ & -0.015 & $-3.55^{*}$ & -0.003 & $-2.12 * *$ & -0.005 & $-5.74 *$ & -0.004 & -1.78 \\
\hline healthinsu e & -0.003 & -1.73 & -0.001 & -0.99 & -0.003 & $-3.4 *$ & -0.003 & -1.49 \\
\hline mills_alco 1 & 0.007 & 0.57 & 0.002 & 0.39 & 0.002 & 0.39 & 0.001 & 0.09 \\
\hline
\end{tabular}

Never Drank $\quad \mathrm{y}=\operatorname{Pr}($ healthstatusoprobit $==1)($ predict $)=0.007471$

Non-Drinkers $\quad \mathrm{y}=\operatorname{Pr}($ healthstatusoprobit $==1)$ (predict $)=0.003514$

Moderate Drinkers $\quad \mathrm{y}=\operatorname{Pr}($ healthstatusoprobit $==1)$ (predict) $=0.00624$

Heavy Drinkers $\quad y=\operatorname{Pr}($ healthstatusoprobit $==1)($ predict $)=0.002681$

(*) dy/dx is for discrete change of dummy variable from 0 to 1

* indicates significance at $1 \%$ and $5 \%$ level 